\title{
A novel linkage map of sugarcane with evidence for clustering of retrotransposon-based markers
}

\author{
Alessandra C Palhares ${ }^{1}$, Taislene B Rodrigues-Morais ${ }^{1}$, Marie-Anne Van Sluys ${ }^{2}$, Douglas S Domingues ${ }^{2,3}$, \\ Walter Maccheroni $\mathrm{Jr}^{4,5}$, Hamilton Jordão Jr ${ }^{4,5}$, Anete P Souza ${ }^{6}$, Thiago G Marconi6 ${ }^{6}$, Marcelo Mollinari ${ }^{1}$, \\ Rodrigo Gazaffi ${ }^{1}$, Antonio Augusto F Garcia ${ }^{1}$ and Maria Lucia Carneiro Vieira ${ }^{1 *}$
}

\begin{abstract}
Background: The development of sugarcane as a sustainable crop has unlimited applications. The crop is one of the most economically viable for renewable energy production, and $\mathrm{CO}_{2}$ balance. Linkage maps are valuable tools for understanding genetic and genomic organization, particularly in sugarcane due to its complex polyploid genome of multispecific origins. The overall objective of our study was to construct a novel sugarcane linkage map, compiling AFLP and EST-SSR markers, and to generate data on the distribution of markers anchored to sequences of sclvana_1, a complete sugarcane transposable element, and member of the Copia superfamily.

Results: The mapping population parents ('IAC66-6' and 'TUC71-7') contributed equally to polymorphisms, independent of marker type, and generated markers that were distributed into nearly the same number of cosegregation groups (or CGs). Bi-parentally inherited alleles provided the integration of 19 CGs. The marker number per CG ranged from two to 39. The total map length was 4,843.19 cM, with a marker density of $8.87 \mathrm{cM}$. Markers were assembled into 92 CGs that ranged in length from 1.14 to $404.72 \mathrm{cM}$, with an estimated average length of $52.64 \mathrm{cM}$. The greatest distance between two adjacent markers was $48.25 \mathrm{cM}$. The sclvana_ 1-based markers (56) were positioned on 21 CGs, but were not regularly distributed. Interestingly, the distance between adjacent sclvana_1-based markers was less than $5 \mathrm{cM}$, and was observed on five CGs, suggesting a clustered organization.

Conclusions: Results indicated the use of a NBS-profiling technique was efficient to develop retrotransposon-based markers in sugarcane. The simultaneous maximum-likelihood estimates of linkage and linkage phase based strategies confirmed the suitability of its approach to estimate linkage, and construct the linkage map. Interestingly, using our genetic data it was possible to calculate the number of retrotransposon sclvana_1 ( 60) copies in the sugarcane genome, confirming previously reported molecular results. In addition, this research possibly will have indirect implications in crop economics e.g., productivity enhancement via QTL studies, as the mapping population parents differ in response to an important fungal disease.
\end{abstract}

Keywords: Saccharum spp, AFLP, EST-SSR, Retrotransposon-based markers, Single-dose markers, Integrated genetic map, Marker distribution

\section{Background}

Sugarcane is a crop of unquestionable importance for tropical and subtropical regions of the world, where it occupied 24 million hectares in 2009 [1]. Sugarcane is a cost effective renewable resource, with alternative production in food, feed, fiber, and energy e.g. sugar, animal

\footnotetext{
* Correspondence: mlcvieir@usp.br

'Departamento de Genética, Escola Superior de Agricultura "Luiz de Queiroz", Universidade de São Paulo, 13418-900, Piracicaba, Brazil

Full list of author information is available at the end of the article
}

feeds, alcohols, and fertilizers. Brazil is one of the greatest producers and exporters of sugar and ethanol from sugarcane, where cane production reached approximately 625 million tons in 2010, and the sugarcane industry generated a gross annual income of approximately US\$ 23 billion [2].

Sugarcane exhibits the most complex genome of any genetically bred crop. Selection based on scientific approaches began in 1888; the first hybridizations were conducted in Java and Barbados, between Saccharum

\section{Biomed Central}

(c) 2012 Palhares et al.; licensee BioMed Central Ltd. This is an Open Access article distributed under the terms of the Creative Commons Attribution License (http://creativecommons.org/licenses/by/2.0), which permits unrestricted use, distribution, and reproduction in any medium, provided the original work is properly cited. 
officinarum and S. spontaneum. S. officinarum, known as 'noble' canes, are high in sucrose with juicy, thick stalks; low in fiber content, and susceptible to several diseases [3]. S. spontaneum is low in sucrose content, but robust, and resistant to abiotic stresses and pests [4]. One hundred years of interspecific hybrid backcrossings with S. officinarum (used as the maternal parent), a process called 'nobilization', lead breeders to obtain more productive varieties, with ratooning ability, and increased resistance to biotic and abiotic stresses [5,6]. Subsequently, all modern sugarcanes derive largely from intercrossing these canes, followed by intensive selection $[7,8]$. Therefore, currently grown cultivars are denoted Saccharum spp. Varieties are evaluated for rusticity, pest resistance, and high sugar yield prior to release, which requires 12 to 15 years.

The contemporary sugarcane cultivars have a large (10 $\mathrm{Gb})$ and complex genome structure that is highly polyploid, aneuploid ( $2 \mathrm{n}=100$ to 130$)$, and have multispecific origins [9] with a complete set of homo(eo)logous genes ranging from 8 to 10 alleles. Classic cytological works as well as fluorescent in situ hybridization determined that $S$. officinarum is an octaploid species $(2 n=8 x=80)$ that experienced few aneuploid events, and the ploidy level of $S$. spontaneum varies from 5 to $16(2 \mathrm{n}=40$ to 128$)[10,11]$. Genome in situ hybridization assays reveal that the 'R570' cultivar $(2 \mathrm{n}=115)$ shares $80 \%$ of its chromosomes with S. officinarum, $10 \%$ with $S$. spontaneum, and $10 \%$ are recombinant chromosomes [12]. These results clearly indicate that two chromosome sets coexist in the sugarcane genome. Vegetative propagation resulted in sugarcane clones with variable chromosome numbers cultivated in field plantations, and numerical and structural alterations continued to accumulate.

Linkage maps are valuable tools to elucidate genetic and genomic organization, particularly in sugarcane due to its increased ploidy levels. However, high inbreeding depression caused by endogamy limits the production of experimental mapping populations, such as $\mathrm{F}_{2}, \mathrm{BCs}$, RILs, and DH lines. The S. spontaneum 'SES 208' $(2 \mathrm{n}=64)$ linkage map published by Al-Janabi et al. [13] was the first map constructed directly from a complex polyploid species, based on single-dose markers (or SDMs) proposed by Wu et al. [14], which considers the use of simplex (single allele copy from one parent) to obtain the genetic map. Al-Janabi et al. [13] used progeny from a cross between 'SES 208', and a diploidized haploid derived from anther cultured 'SES 208' and 'ADP 85-0068' to estimate linkage. This strategy facilitated direct meiotic analysis in 'SES 208', and gametic segregation ratios to be observed. Results showed autopolyploid chromosomal behavior in 'SES 208', and the proportion of SDMs to higher dose markers (multiple alleles) fit the assumption of auto-octaploidy, with the absence of repulsion phase linkages. Subsequently, da Silva et al. [15] integrated the map of Al-Janabi et al. [13] with the simplex-based map of Sobral et al. [16]. SDMs linkage relationships were determined using MapMaker software [17].

Later, Grivet et al. [18] used selfed progeny to estimate linkage for the elite cultivar 'R570'. To date, selffertilized sugarcane progeny are used to map simplex and duplex markers on co-segregation groups (CGs); for instance, Andru et al. [19] using the software JoinMap 3.0 [20] constructed a map for the cultivar Louisiana 'LCP 85-384'. Alternatively, crossing unrelated heterozygous genotypes generates a segregating sibling population $\left(\mathrm{F}_{1}\right)$, which can be valuable for constructing outcrossing species maps, including mapping in sugarcane. From the genetic configurations expected in a segregating $\mathrm{F}_{1}$, and denoting gel band presence as $A$, and its absence as $O$, we can make use of the designation $A O x$ $O O$ (in a diploid species), or Simplex $x$ Nuliplex (in sugarcane) to construct individual maps, one for each parent. This approach, known as the pseudo testcross strategy [21] uses two sets of dominant markers that segregate in a 1:1 ratio. It was applied to estimate linkage in interspecific crosses, where $S$. officinarum was the female ('Green German', 'IJ 76-514', 'La Striped'), and S. spontaneum the male parent ('IND 81-146' and 'SES 147B') [22-26]. The Australian cultivars 'MQ77-340', 'Q165', and 'MQ76-53' were mapped similarly [27-29]. Each of these studies determined a comparable number of linkage groups (LGs) and map lengths; e.g. 'La Striped' $(2 \mathrm{n}=80): 49$ LGs, 1,732 cM; 'SES 147B' $(2 \mathrm{n}=64)$ : 45 LGs, $1,491 \mathrm{cM}$ [26].

Garcia et al. [30] constructed a single integrated genetic map based on simultaneous maximum-likelihood linkage estimates and linkage phase methodology [31], based on a population derived from a cross between two pre-commercial sugarcane cultivars ('SP80-180' $x$ 'SP804966 '). A total of 1,118 single-dose markers were identified; 39\% were derived from a testcross configuration between parents segregating in a $1: 1$ ratio, and $61 \%$ segregated in 3:1 ratio, representing heterozygous loci in both parentals with identical genotypes. The final map was comprised of 357 linked markers, including RFLPs, SSRs, and AFLPs assigned to 131 CGs, with a LOD score of 5.0, recombination fraction of $37.5 \mathrm{cM}$. Authors indicated the simultaneous maximum-likelihood estimates of linkage, and linkage phases were appropriate to generate an integrated genetic map of sugarcane [30]. Then, to enhance existing map resolution, and identify putative functional polymorphic gene loci, Oliveira et al. [32] screened EST-SSRs and EST-RFLPs in the same mapping population. Markers analyzed in the previous map were added to 2,303 newly generated polymorphic 
markers, including 1,669 (72.5\%) SDMs; 664 (40\%) were scattered on 192 CGs, with a total estimated length of 6,261 cM.

The current development of expressed sequence-based markers such as EST-SSRs, genic SNPs, and TRAPs enrich the genetic data that comprise linkage maps. In sugarcane, due to the necessity of mapping a large number of markers to guarantee a reasonable coverage of its genome with many chromosomes [33], a novel and potentially useful approach is to compile anonymous and putative functional markers. Earlier, the Brazilian Sugarcane Expressed Sequence Tag (or SUCEST) project [34,35] generated 237,954 high-quality ESTs organized into 43,141 putative unique sugarcane transcripts referred to as sugarcane assembled sequences. Based on SUCEST data, Rossi et al. [36] developed RFLPs using probes derived from NBS-LRR and LRR conserved domains, and S-T Kinase type resistance genes, and positioned them on the 'R570' map. Besides, Rossi et al. [37] conducted a transposable element (TE) search, revealing a surprising high number of expressed TE homologues, and found all major transposon families were represented in sugarcane. Mutator and Hopscotch were later reported as the most represented TE families in the sugarcane transcriptome [38]. The SUCEST database was used to describe two LTR retrotransposon families, which were denoted as scIvana_1 and scAle_1 [39]. Both were reported as complete elements, and different members of the Copia superfamily. The scIvana_1 shows low copy numbers (40 to 50) and diversity among copies, and is expressed under specific conditions in lowdifferentiated tissues; scAle_1 exhibits high copy numbers in the sugarcane genome (>1000), is more diversified compared to scIvana_1, and active under varied physiological conditions.

Retrotransposon-based markers have been developed using several approaches. In Poaceae species, for example, SSAP was first used to study the distribution of $B A R E$-1-like retrotransposable elements in barley genome [40]. In brief, SSAP uses two restriction enzymes to generate a large number of DNA fragments; after that, a retrotransposon-anchored PCR is used to perform a selective amplification. In the 90's, two new techniques were developed to exploit the polymorphism generated by $B A R E-1$ genome integration, named REMAP and IRAP [41]. Patterns indicate that although the BARE-1 family of retrotransposons is dispersed, these elements are clustered or nested locally, and often found near microsatellite sequences. Later, both procedures were reported as useful to screen insertional polymorphisms in populations of Spartina anglica, an allopolyploid involved in natural and artificial invasions [42]. These methods are dominant and multiplex, and generate anonymous marker bands. IRAP is based on the PCR amplification of genomic DNA fragments which lie between two retrotransposon insertion sites, and REMAP is based on the amplification of fragments which lie between a retrotransposon insertion site and a microsatellite site. Polymorphism is detected by the presence or absence of the PCR product in both techniques. Lack of amplification indicates the absence of the retrotransposon at the particular locus. In contrast, the RBIP [43] and ISBP [44] score individual loci and are used to search for insertional polymorphisms. RBIP, for example, was used to address the issue of evolution of rice varieties [45] and ISBP was used to analyze diversity in wheat [46]. The RBIP method exploits knowledge of the sequence flanking a TE to design the primers while the ISBP method uses one primer in the element and the other in the flanking DNA sequence.

The overall objective of our study was to generate data on scIvana_1 and scAle_1-based marker distribution to a novel sugarcane linkage map based on a compilation of AFLPs and EST-SSRs.

\section{Results}

\section{Genotyping and segregation analyses}

Excellent AFLPs, EST-SSRs, and scIvana_1-based marker banding profiles were obtained [see Additional file $1]$, despite the size and complexity of the sugarcane genome. The 72 enzyme-selective primer combinations tested provided a range of AFLP band numbers per gel (44 to 174), and polymorphic loci (four to 33 ). Subsequently, 22 combinations were selected as optimal for genotyping the $F_{1}$ population [Additional file 2]. The combinations generated 102 to 172 AFLP bands per gel, and 19 to 48 polymorphic loci, which revealed $22.1 \%$ $(685 / 3,094)$ segregating loci. Among the segregating loci, $71.2 \%(488 / 685)$ segregated in only one parent, and $28.8 \%(197 / 685)$ segregated in both parents (Table 1). The 'IAC66-6' clone and 'TUC71-7' variety contributed a respective $52 \%(254 / 488)$ and $48 \%(234 / 488)$ of the loci that segregated in only one parent. The average number of amplified bands and segregating loci per enzymeprimer combination were $140.6(3,094 / 22)$ and 31.1 (685/22), respectively.

From the 184 EST-SSR loci initially investigated, 22.3\% (41) were selected for genotyping [Additional file 2]. These loci revealed 273 alleles with an average of 6.7 alleles per locus; $80.6 \%$ (220) segregated in the $F_{1}$ population, 68.6\% (151/220) segregating in only one parent, and $31.4 \%(69 / 220)$ in both parents (Table 1). The 'IAC66-6' clone and 'TUC71-7' variety contributed a respective $43 \%(65 / 151)$ and $57 \%(86 / 151)$ of the alleles that segregated in only one parent.

Among the 16 restriction enzyme-primer combinations used to amplify the retrotransposon sclvana_1-based markers, six were selected for genotyping the $F_{1}$ population. 
Table 1 Marker polymorphisms used for mapping, and distribution of the different markers according to the cross type (D1, D2 and C)

\begin{tabular}{|c|c|c|c|c|}
\hline Marker type & AFLP & EST-SSR & sclvana_1 & Total \\
\hline Number of scorable bands (evaluated in total) ${ }^{a}$ & 3,094 & 273 & 357 & 3,724 \\
\hline Number of segregating markers (genotyped) & 685 & 220 & 87 & 992 \\
\hline Number of polymorphic markers between parents & 488 & 151 & 74 & 713 \\
\hline Number of monomorphic markers between parents & 197 & 69 & 13 & 279 \\
\hline Number of single dose markers (SDMs) ${ }^{b}$ & 535 & 130 & 65 & 730 \\
\hline SDMs of origin from 'IAC66-6' [D1] ${ }^{\mathrm{C}}$ & 197 & 41 & 23 & 261 \\
\hline SDMs of origin from 'TUC71-7' [D2] ${ }^{\mathrm{C}}$ & 192 & 60 & 32 & 284 \\
\hline SDMs of origin from both parents $[C]^{d}$ & 146 & 29 & 10 & 185 \\
\hline Total number of linked markers on the map & 395 & 95 & 56 & 546 \\
\hline Number of linked markers of origin from 'IAC66-6' [D1] & 154 & 33 & 21 & 208 \\
\hline Number of linked markers of origin from 'TUC71-7' [D2] & 164 & 46 & 30 & 240 \\
\hline Number of linked markers of origin from both parents [C] & 77 & 16 & 5 & 98 \\
\hline
\end{tabular}

${ }^{a}$ AFLPs generated from 22 enzyme-selective primer combinations, EST-SSR alleles generated from 41 loci and sclvana_1-based markers generated from 6 restriction enzyme-primer combinations.

${ }^{b}$ Data obtained after Bonferroni's correction.

c Markers present in only one parent with a 1:1 segregation ratio in the mapping population.

${ }^{d}$ Markers present in both parents with a 3:1 segregation ratio in the mapping population.

These combinations revealed 357 loci; 24.4\% (87) behaved as segregating loci. Among them, 85.1\% (74/87) and 14.9\% $(13 / 87)$ segregated in only one parent and in both parents, respectively (Table 1 ). The average number of amplified bands and segregating loci per enzyme-primer combination were $59.5(357 / 6)$ and $14.5(87 / 6)$, respectively [Additional file 2]. The male and female parents contributed a respective $44.6 \%(33 / 74)$ and $55.4 \%(41 / 74)$ of loci that segregated in only one parent. Sixteen retrotransposon scAle_1 combinations revealed gel profiles; however, amplicon absence, or amplifications associated with nonspecific polymorphism prevented profile use in genotyping.

AFLP and scIvana_1-based loci exhibited similar levels of segregating alleles in the mapping population ( 25\%). Notably, both techniques reveal polymorphisms at restriction enzyme cleavage sites. On the other hand, ESTSSR loci showed high levels of segregating alleles in the mapping population ( $80 \%)$. The polymorphisms observed at EST-SSR loci are due to differences in the size of multiple alleles; we cannot predict if any allele will be fixed in a sugarcane cultivar, which is expected to be highly heterozygous. Both parents contributed equally to polymorphisms i.e. $49.4 \% \pm 3.7 \%$ and $50.6 \% \pm 3.8 \%$ of the amplicons derived from the male ('IAC66-6') and female ('TUC71-7') parent, respectively, independent of marker type.

It is important to clarify that we organized our segregation data assuming that homo(eo)logous chromosomes paired faithfully during meiosis, leading to regular bivalent formation as well as normal gametes. It is imperative to emphasize that sugarcane is an artificial genome, highly polyploid, aneuploid, and has interspecific origins, which impedes our capacity to designate codominant markers at any locus. Consequently, loci were divided into heterozygous in one parent and null in the other (simplex $x$ nuliplex), and heterozygous in both parents (simplex $x$ simplex). Based on this model, all markers were scored as dominant (or binary), and were assigned to the expected segregation ratios i.e. 1:1 and 3:1 (Table 1).

A total of 992 segregating loci were genotyped in the mapping population; 685 AFLPs (generated from 22 enzyme-selective primer combinations), 220 ESTSSRs (derived from 41 loci), and 87 sclvana_1-based loci (obtained from six enzyme-primer combinations). The expected segregation ratios at each locus (992) were checked using Chi-square tests, adjusting for multiple tests using Bonferroni correction. Then, 730 (73.6\%) loci were safely used to build the map, being 535 AFLPs, 130 EST-SSRs, and 65 sclvana_1-based loci. The global level of significance used to determine the validity of the segregation ratios of $1: 1$ and $3: 1$ was 5.04e-05 (alpha $=0.05 / 992)$.

\section{The genetic map and marker distribution within co-segregation groups}

The marker number used to perform linkage analyses was 730; 261 were derived from 'IAC66-6' (here indicated as D1), 284 from 'TUC71-7' (or D2), and 185 were present in both parents (or C). The final sugarcane map was comprised of 546 markers assembled into 92 cosegregation groups (CGs), and 184 markers not assigned to any CG. Coincidently, D1 (208) and D2 (240) markers 
were distributed into nearly the same number of CGs (51 and 55, respectively). By using the loci that segregated in a 3:1 fashion (98) as bridges, we provided the integration of 19 CGs (I-1, I-2, I-3, I-4, I-6, I-8, I-9, I-12, II-1, II-3, III-1, IV-1, VII-1, U-1, U-2, U-3, U-8, U-13, and U-33). The marker number per CG ranged from two to 39 (Figure 1). The total map length was $4,843.19 \mathrm{cM}$, with a marker density of $8.87 \mathrm{cM}$. The CG length covered a range from 1.14 to $404.72 \mathrm{cM}$, with an estimated average of $52.64 \mathrm{cM}$. The greatest distance between two adjacent markers was 48.25 cM (CG I-3).

Forty-one CGs (44.6\%) were assembled into seven putative independent homo(eo)logous groups (HGs), which were recognized based on 82 alleles generated by 24 EST-SSR loci. The remaining loci (ESTB189, ESTB191, CV11, and CV86) did not contribute to CG assembly; only one allele was positioned on the respective HG. The CG number assembled into HGs ranged from two to 15, the largest (HGI) contained 210 markers, and the smallest (HGVII) six markers, which was clearly a very non-uniform distribution (Figure 1). Eight previously mapped EST-SSR loci [32] were placed here on HGI (ESTA53, ESTB94, ESTB100, and ESTB118), HGIII (ESTA48), HGIV (ESTC80 and ESTB99), and HGV (ESTB60).

The mapped proportion of scIvana_1-based loci was 86.2\% (56/65), greater than AFLPs $(73.8 \%, 395 / 535)$ and EST-SSRs (73.1\%, 95/130). The scIvana_1-based loci (56) were positioned on $21 \mathrm{CGs}$, which were represented in four HGs. However, there is some evidence that these markers may not be regularly distributed (Figure 1); only one marker was placed in groups I-6, I-13, III-3, III-4, $\mathrm{U}-1, \mathrm{U}-2, \mathrm{U}-4, \mathrm{U}-7$ and $\mathrm{U}-8$, and more than five markers were placed in groups I-1, I-3, and IV-1. The evidence for clustering of scIvana_1-based markers was verified by the Chi-square goodness-of-fit test that results in a p-value 4.64e-04. This model has been used for testing if marker distribution deviates significantly from a random distribution in genetic maps i.e. segregating as expected in a Poisson distribution [47]. The number of regions with two (6) and three (1) adjacent markers was higher than expected only by chance ( 2 and 0.09 , respectively). Interestingly, distances between some of the adjacent scIvana_1-based markers were lower than $5 \mathrm{cM}$, notably in groups, I-1, I-2, III-2, IV-1, and U-51 (Table 2). This value was the same used by Rossi et al. [36] to define NBS/LRR RGA clusters.

We subsequently obtained the total scIvana_1-based marker numbers (357), divided by the number of enzyme-primer combinations used to obtain the amplicons (6), and the result was $\sim 60$. We propose this as the number of retrotransposon scIvana_1 copies in the sugarcane genome. Similarly, by obtaining the total number of scIvana_1-based markers each parent contributed separately, the following results correspond to the number of scIvana_1 copies in the respective 'IAC66-6' and 'TUC71-7' genomes: 53 (316/6) and 54 (324/6).

However, the total number of scAle_1-based fragments was 1008. Nine restriction enzyme-primer combinations were used to amplify the scAle_1-based fragments, an average of 112 per combination. The results did not facilitate the identification of any clear polymorphisms in the gels. Consequently, the data were not used for mapping studies.

\section{Molecular validation of sclvana_1-based fragments}

Twenty-five scIvana_1-based markers selected for genotyping were sequenced; and 64\% (16/25) showed homology with known nucleotide sequences deposited in GenBank (Table 3). Most (13 sequences) showed homology with scIvana_1 sequences, and others showed homology to Zea mays (DIsIvSI337), Oryza minuta (DIsIvSI390, DIsIvSI412), and Sorghum bicolor (SIsIvSI180) sequences. The DIsIvLI228 fragment also exhibited homology with a Saccharum chloroplast sequence. Six of the sequences were mapped, DIsIvSI163, DIsIvSI208, DIsIvSI160, SIsIvLI240, SIsIvLI412, and DIsIvLI415, and two were tightly linked with EST-SSRs. The DIsIvSI337 fragment was submitted for tblastx search, and revealed similarity with a hypothetical, highly conserved protein of unknown function in Arabidopsis thaliana, and other species. Similarly, DIsIvSI390 and DIsIvSI412 fragments were aligned with an Oryza minuta sequence; tblastx indicated similarity with a hypothetical protein of unknown function. The SIsIvSI180 fragment exhibited similarity to two Sorghum sequences, one to a retrotransposon of S. bicolor [48]. Finally, the DIsIvLI228 fragment exhibited a certain identity with a ribosomal protein chloroplast sequence of Saccharum 'SP80-3280' (Table 3).

\section{Discussion}

AFLPs have been used to assess genetic diversity in germplasm collections of sugarcane and close relatives [49-52], and to build linkage maps [19,53]. In light of these studies, AFLPs have been informative in generating a substantial amount of unambiguous polymorphic markers. For example, Andru et al. [19] reported 64 AFLP restriction enzyme-primer combinations, and detected 816 polymorphic loci; in the present study, 22 combinations revealed 685 polymorphic loci. We suggest the differences were the result of the genotyping population, the first with increased homozygosity $\left(S_{1}\right.$ progeny) relative to a segregating $F_{1}$ population. In both studies, AFLPs were a viable marker to build a scaffold for other marker types, including expressed sequence-based markers, which could be positioned on the scaffold. Furthermore, this scaffold is particularly important in 


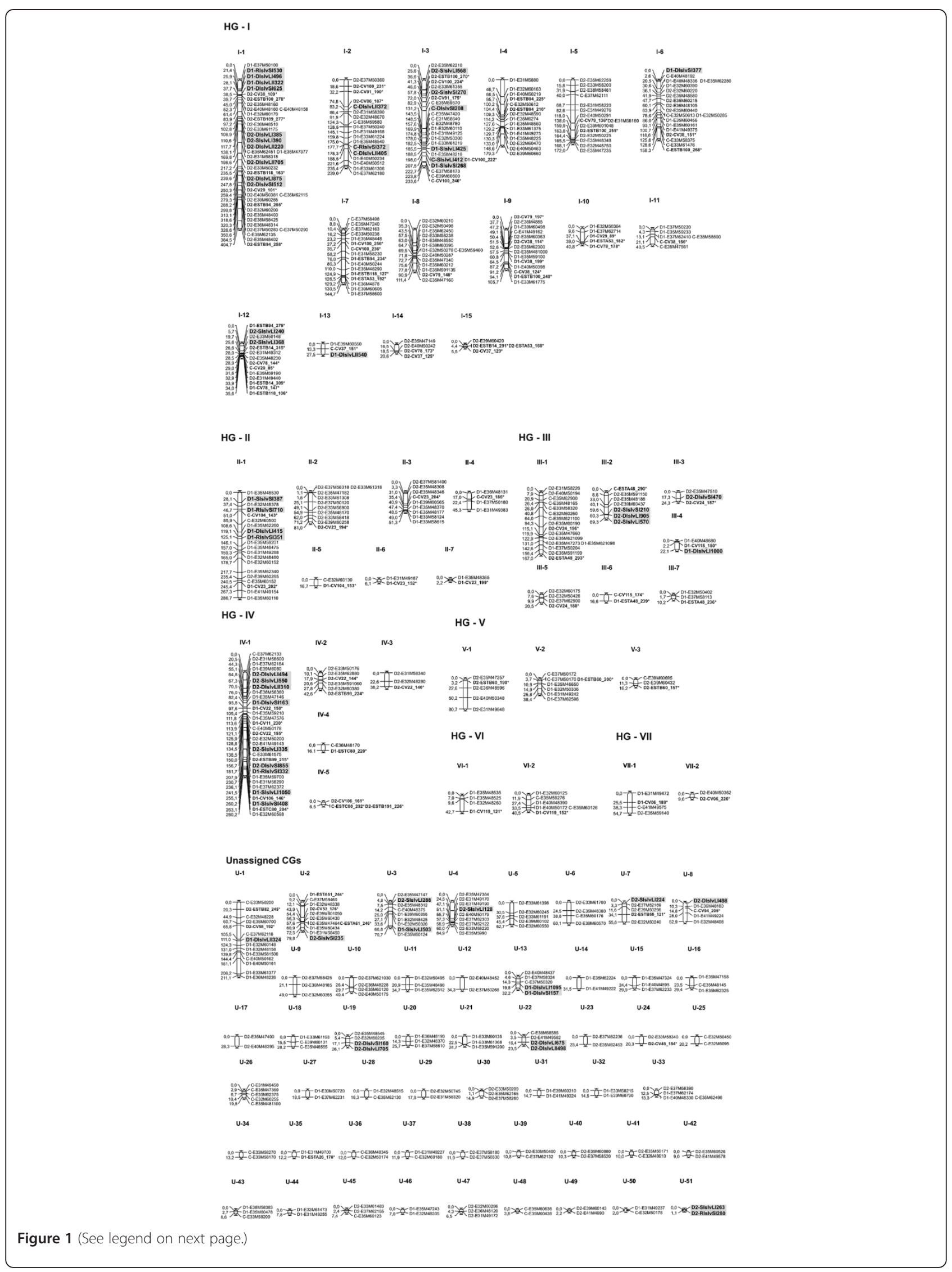


(See figure on previous page.)

Figure 1 Linkage map of the population 'IAC66-6' $\boldsymbol{x}$ 'TUC71-7'. Genetic distances between adjacent markers are shown on the left of each co-segregation group (CG). AFLPS constitute the map scaffold; EST-SSR loci appear in bold with asterisk symbols, and sclvana_1-based markers are depicted in bold in a gray box. The final map was constructed with 546 markers associated with 92 CGs (in Arabic numerals). Forty-one CGs (42.7\%) were assembled into seven putative independent HGs (in Roman numerals). Other CGs (51) were denoted as unassigned groups (U). Note the clustered tendency of some sclvana_1-based markers.

sugarcane, as expressed sequences are physically too far apart.

From the 22 enzyme-selective primer combinations selected in this study to detect AFLPs, 14 were previously tested to build maps for the 'R570' cultivar [53], the S. officinarum 'IJ 76-514' clone, and 'Q165' [28], 'Q117' and 'MQ77-340' [27] cultivars as well as for the $\mathrm{F}_{1}$ population 'SP80-180' $x$ 'SP80-4966' [30]. Based on shared AFLPs and SSRs, the map comparisons of 'R570', 'Q165, 'Q117', and 'MQ77-340' cultivars were done [33]; several co-segregation groups (CGs) were aligned, and homo(eo)logous groups (HGs) associated, which received the same designation. As several common alleles were positioned, therefore suitable data should be available to construct a reference map for sugarcane commercial varieties, despite the pedigree complexity. For instance, a comparison between the map built based on the present study and the one published by Pastina et al. [54] is possible. Both are integrated linkage maps that share some common SSRs. In both maps, ESTA53, ESTB94, ESTB100 and ESTB118 were assigned to HGI as well as ESTA48 was mapped in the same grouping, HGIII. In addition, HGV contains three CGs that share the ESTB60 locus, which was assigned to HGVII of Pastina's map [54]. This suggests a possible correspondence between these HGs.

Several authors have applied SSR markers to estimate linkage in sugarcane $[19,30,32,33]$. Due to the multiallelic nature and relative abundance of SSRs in plant genomes, they have utility to identify HGs in polyploid species [33]. Based on this principle, Rossi et al. [36] identified 66 CGs (of 128) assembled into seven HGs from the French cultivar 'R570' linkage map. Similarly, Aitken et al. [28] identified $136 \mathrm{CGs}$ assembled into eight HGs from the Australian cultivar 'Q165' linkage map. Oliveira et al. [32] identified 120 CGs (of 192) assembled into 14 HGs from a map of the progeny derived from a single cross between 'SP80-180' and 'SP80-4966'.

Here, we compiled 41 CGs (of 92) into seven putative HGs. Interestingly, six EST-SSR loci were duplicated within chromosomes CV22, CV38, CV78, CV100, ESTB14, and ESTB94, which were positioned on HG I and IV (Figure 1). Duplicated genomic regions were reported to occur in various sugarcane maps $[23,28,32,33]$, and are possibly a consequence of the multispecific origins of the modern cultivars. Structural genomic rearrangements, including the movement of transposable elements (TEs) may also explain the duplications [55].

We used an innovative approach by mapping transposon-based markers in sugarcane using the NBSprofiling technique. In other plant species, TEs have been mapped using SSAP. This marker system was applied in barley (namely the TE BARE-1) [40], wheat (TEs, Wis2A$1 A$ and BARE-1) [56], lettuce, (Tls1 and Tls2) [57], and tomato (ToRTL1, T265 and Tnt1) [58]. Due to the advanced knowledge in tomato genetics, it was possible to determine that polymorphic insertions were primarily located in the centromeric regions. Both the abovementioned approaches increase the available information regarding retrotransposon distribution over plant linkage groups. The NBS-profiling protocol efficiently targeted scIvana_1 retrotransposon sequences and, at the same time, produced a polymorphic multilocus marker profile that was enriched for these sequences. Both the SSAP approach and the NBS-profiling technique investigate polymorphic restriction sites and the presence or absence of the retrotransposon sequence. SSAP uses two restriction enzymes (one with frequent cut sites and the other with rare cut sites), generating a large number of DNA fragments before performing the selective amplification. PCR results from the use of a primer that is complementary to the adaptor sequence and other complementary to the retrotransposon sequence. Since we have to choose two enzymes which have no recognition sites for restriction in the retrotransposon sequence, it reduces the number of combinations (enzyme/primer) to be tested. The NBSprofiling technique only uses one restriction enzyme (with frequent or rare cut sites), generating a small number of DNA fragments to be selected and consequently be stained and visualized separately in the gel. This is especially important considering the large genome size of sugarcane. Using enzymes that have no recognition sequences in the retrotransposon scIvana_1 (combined with primers complementary to its sequence), it was possible to estimate the number of copies of this element in the genome.

Among the 16 restriction enzyme-primer combinations used to amplify scIvana_1, the enzymes DraI and $S s p$ I resulted in an increased number of scorable bands and polymorphic loci compared to $A l u \mathrm{I}$ and RsaI. Earlier studies have shown rare-cutting enzymes such as DraI and $S s p$ I are more suitable for restricting sugarcane DNA due to its large size. However, enzymes that 
Table 2 Retrotransposon clustering and its position into the sugarcane genetic map

\begin{tabular}{|c|c|c|c|c|}
\hline \multirow[t]{2}{*}{ Cluster $^{a}$} & \multirow[t]{2}{*}{ Markers } & \multirow[t]{2}{*}{ Cluster size $^{\mathrm{a}}$ (cM) } & \multicolumn{2}{|c|}{ Map position ${ }^{b}$} \\
\hline & & & HG & CG \\
\hline 1 & D1-RIsIvSI530, D1-DIsIvLI496, D1-DIsIVLII322 & 6.64 & । & $1-1$ \\
\hline 2 & D2-DIsIvLI385, D2-SIsIVLI390 & 1.74 & । & $1-1$ \\
\hline 3 & C-RIsIvSI372, C-DIsIvLII405 & 0.61 & 1 & $1-2$ \\
\hline 4 & D2-SIsIvSI210, D2-DIsIvLI905 & 0.7 & III & || $\mid-2$ \\
\hline 5 & D2-DIsIvLI494, D2-SIsIvLI550, D2-DIsIvLII310 & 5.66 & IV & IV-1 \\
\hline 6 & D2-SIsIVLI263, D2-RIsIvSI280 & 1.14 & - & $U-51$ \\
\hline
\end{tabular}

${ }^{a}$ Defined by the distance between the flanking markers.

${ }^{\mathrm{b}} \mathrm{HG}$, homo(eo)logous groups; CG, co-segregation groups.

frequently cut sugarcane DNA have the potential to generate an enormous number of fragments, and consequently affect other protocol steps, and subsequent results. All enzyme-primer combinations resulted in non-amplification for scAle_1. Primer design was challenging due to sequence diversity among scAle_1 copies. When amplicons were obtained, all combinations resulted in $\sim 112$ bands per gel, which prevented polymorphism identification. Alternatively, a reduction in the number of bands per gel can be reached by adding selective bases at the 3'-end of PCR primers, as previously demonstrated in barley [40]. Queen et al. [56] used SSAP to study the elements Wis $2 A-1 A$ and BARE-1 in wheat, and four selective nucleotides were added as an attempt to reduce the number of amplified fragments. Both elements are known to have 1,000 copies in the wheat genome, and good results were obtained for genotyping and mapping when applying this strategy. Besides this, we should try to produce markers derived from scAle_1 subfamilies, therefore having an estimate of the number of copies of each subfamily in the sugarcane genome.

The mean number of amplicons obtained by restriction enzyme-primer combinations was very similar to the number estimated by molecular methods; 40 to 50 copies of sclvana_1 were detected in the sugarcane genome, and scAle_1 exceeded 1,000 copies [39]. These results were congruent with 56 scIvana_1-based loci

Table 3 sclvana_1-based fragments with homology to nucleotide sequences deposited in GenBank $\left(e-v a l u e<e^{-5}\right.$ )

\begin{tabular}{|c|c|c|c|c|}
\hline Marker code & Size (bp) & GenBank accession no. & Homology & E-value $^{a}$ \\
\hline DIslvSI & 138 & DQ115032.1 & Saccharum 'SP80-3280' clone SCCCCL6002A07 Tnt1-like, partial sequence & $2 e-27$ \\
\hline DIslvSI & 160 & DQ115032.1 & Saccharum 'SP80-3280' clone SCCCCL6002A07 Tnt1-like, partial sequence & $8 e-27$ \\
\hline DIslvSI & 208 & DQ115032.1 & Saccharum 'SP80-3280' clone SCCCCL6002A07 Tnt1-like, partial sequence & $5 e-29$ \\
\hline DIslvSI & 310 & DQ115032.1 & Saccharum 'SP80-3280' clone SCCCCL6002A07 Tnt1-like, partial sequence & $2 \mathrm{e}-28$ \\
\hline DIslvSI & 337 & EU969904.1 & Zea mays clone 337091 mRNA sequence & $6 e-28$ \\
\hline \multirow[t]{3}{*}{ DIslvSI } & 390 & DQ115032.1 & Saccharum 'SP80-3280' clone SCCCCL6002A07 Tnt1-like, partial & $5 e-178$ \\
\hline & & & sequence & \\
\hline & & AC216031.1 & Oryza minuta clone OM_Ba0016E09, complete sequence & $1 e-70$ \\
\hline \multirow[t]{2}{*}{ DIslvSI } & 412 & DQ115032.1 & Saccharum 'SP80-3280' clone SCCCCL6002A07 Tnt1-like, partial sequence & $2 \mathrm{e}-147$ \\
\hline & & AC216031.1 & Oryza minuta clone OM_Ba0016E09, complete sequence & $4 \mathrm{e}-60$ \\
\hline SIslvSI & 158 & DQ115032.1 & Saccharum 'SP80-3280' clone SCCCCL6002A07 Tnt1-like, partial sequence & $2 e-28$ \\
\hline \multirow[t]{2}{*}{ SIslvSI } & 180 & AC169373.2 & Sorghum bicolor clone SB_BBc0188M08, complete sequence & $3 e-36$ \\
\hline & & FN431662.1 & Sorghum bicolor BAC contig 24P17C, cultivar Btx623 & $1 e-34$ \\
\hline SIslvSI & 245 & DQ115032.1 & Saccharum 'SP80-3280' clone SCCCCL6002A07 Tnt1-like, partial sequence & $2 e-28$ \\
\hline SIslvSI & 330 & DQ115032.1 & Saccharum 'SP80-3280' clone SCCCCL6002A07 Tnt1-like, partial sequence & $2 e-28$ \\
\hline RIslvSI & 195 & DQ115032.1 & Saccharum 'SP80-3280' clone SCCCCL6002A07 Tnt1-like, partial sequence & $5 e-29$ \\
\hline DIslvLI & 228 & AE009947.2 & Saccharum 'SP-80-3280' chloroplast, complete genome & $3 e-90$ \\
\hline DIslvLI & 272 & DQ115032.1 & Saccharum 'SP80-3280' clone SCCCCL6002A07 Tnt1-like, partial sequence & $9 e-106$ \\
\hline DIslvLI & 415 & DQ115032.1 & Saccharum 'SP80-3280' clone SCCCCL6002A07 Tnt1-like, partial sequence & $2 e-93$ \\
\hline DIslvLI & 605 & DQ115032.1 & Saccharum 'SP80-3280' clone SCCCCL6002A07 Tnt1-like, partial sequence & $2 e-102$ \\
\hline
\end{tabular}

${ }^{\text {a }}$ All are standard nucleotide-nucleotide BLASTn scores. 
positioned on the linkage map, exhibiting preferential cluster distribution along 21 CGs. In large-genome cereals, Bennetzen [59] reported retrotransposon distribution as nested insertions in highly heterochromatic transposon clusters. Later, authors reported there appears to be some clustering of TE BARE-1/Wis-2-1 Abased markers on the linkage map of wheat [56], and transposon cluster interference with recombination machinery acting in adjacent euchromatic regions in maize [60]. When additional genomic data is available for sugarcane, it will be interesting to investigate if genes adjacent to retrotransposon clusters are less recombinogenic. Dooner and $\mathrm{He}$ [60] suggested the more condensed chromatin state of retrotransposon clusters in maize might interfere with recombination machinery access in adjacent euchromatic regions. Additionally, in a recent review published by Kalendar et al. [61] authors indicated that at least in cereals and citrus retrotransposons are often locally nested one into another and in extensive domains that have been referred to as 'retrotransposon seas' surrounding gene islands.

We are possibly facing an association between clustered retrotransposon sequences, the inhibition of DNA recombination, an explanation of the small map distance between adjacent retrotransposon-based markers, and the element copy number in plant the genome. This should explain scIvana_1 properties, such as low copy numbers $(\sim 60)$ with expression and mobility under strict control, conversely against the properties of scAle_1 retrotransposons. Therefore, mapping $s c A l e_{-} 1$ element is of great interest, as well as the location of these two elements in chromosome regions.

The segregation results presented here independently indicated that AFLPs, EST-SSRs, or scIvana_1-based loci were consistent with the outcome of former studies $[26,28,32,53,62]$ i.e. most markers $(\sim 70 \%)$ were SDMs. Furthermore, a substantial number were unassigned markers, in addition to variation in the marker number per CG.

The genetic map constructed here ('IAC66-6' $x$ 'TUC71-7') has 546 SDMs covering 4,843 cM that were ordered in 92 CGs, with a marker density of $8.87 \mathrm{cM}$. The genetic map recently published by Pastina et al. ('SP80-180' $x$ 'SP80-4966') has 317 markers covering $2,468 \mathrm{cM}$ that were ordered in $96 \mathrm{CGs}$, with a marker density of $7.5 \mathrm{cM}$ [54]. These are both integrated maps constructed based on segregating $F_{1}$ populations. Note that the number of CGs is somewhat high in Pastina's map, but it is shorter and denser. Cultivar maps are established using self-fertilized populations, and therefore are not comparable to other maps built based on different backgrounds. For instance, the 'LCP 85-384' map has 784 markers covering 5,617 cM that were assigned to 108 CGs, with a marker density of $7.16 \mathrm{cM}$ [19], and 'Q165' map has 910 markers covering 9,058 cM that were assigned to 116 CGs, with a marker density of $9.95 \mathrm{cM}$ [28]. Note that, in this case, the shorter and denser map is the one with a low number of CGs.

Enhancement of sugarcane genetic maps should include additional segregation ratios in mapping analyses, and an increased number of informative SNP- and SSRloci segregating in larger populations. In addition, there is a need for meiotic studies that it is an important component of future studies in deciphering the genetic configuration of sugarcane genotypes.

Finally, it is important to note that the parents of the mapping population differ in response to the Sporisorium scitamineum infection; therefore we expect that offspring segregate for this trait. Consequently, the genetic map established here should be used to localize quantitative loci. It will certainly contribute to a better view on the genetic architecture of smut resistance in sugarcane, as little is known on this subject $[63,64]$. As recently shown in Pastina et al. [54] integrated genetic maps are useful for mapping QTLs. Based on interval mapping and mixed models, authors map QTL effects on a segregating progeny from a cross between two precommercial cultivars. The same approach should be interesting to be applied using the present map that includes retrotransposon-based markers. Moreover, we should improve McNeil et al.'s strategy [65] by aligning marker sequences tightly linked to QTLs for smut resistance with data from the sugarcane genome sequencing project currently underway [66].

\section{Conclusions}

The results of this study showed that AFLPs are a viable marker to create a scaffold for a linkage map, where other marker types can be positioned including expressed sequence-based markers. Results indicated the use of a NBS-profiling technique was efficient to develop retrotransposon-based markers in sugarcane. The simultaneous maximum-likelihood estimates of linkage and linkage phase based strategies confirmed the suitability of its approach to estimate linkage, and construct the linkage map. Interestingly, using our genetic data it was possible to calculate the number of retrotransposon scIvana_1 $(\sim 60)$ copies in the sugarcane genome, confirming previously reported molecular results. In addition, this research possibly will have indirect implications in crop economics e.g., productivity enhancement via QTL studies, as the mapping population parents differ in response to an important fungal disease.

\section{Methods}

\section{Plant material and genomic DNA extraction}

The mapping population was composed of 188 individuals derived from a single cross between 'IAC66-6' and 'TUC71-7'. The male parent 'IAC66-6' is a clone with 
low sucrose content, large diameter stems, and is susceptible to sugarcane smut, a fungal disease caused by Sporisorium scitamineum; the female parent, the Argentinean variety 'TUC71-7', exhibits a higher sucrose content, lower diameter stems, and resistance to smut disease. This disease limits the use of recent highyielding sugarcane varieties developed in Brazil. The cross was made under field conditions at the CanaVialis/ Monsanto Company experimental station, located in the northeastern state of Alagoas, Brazil (S 09³9'57"; W $\left.35^{\circ} 44^{\prime} 07^{\prime \prime}\right)$. Sugarcane successfully flowers and sets seed at the locality due to light period duration (photoperiod), and plants were therefore cultivated at this site. Seeds were harvested, germinated in plastic boxes, and transported to the southeastern state of São Paulo (S 22¹9'49"; W $\left.47^{\circ} 10^{\prime} 21^{\prime \prime}\right)$ for field cultivation.

DNA was isolated from young leaves of $\mathrm{F}_{1}$-progeny and parental plants using the CTAB-based extraction procedure [67], with minor modifications. DNA concentrations were carefully estimated following electrophoresis on ethidium bromide-stained agarose gels using molecular weight standards; aliquots of $50 \mathrm{ng} / \mu \mathrm{l}$ were prepared following quantification.

\section{Generation of AFLP profiles}

AFLPs were amplified based on the protocol described by Vos et al. [68] and applied to sugarcane. Briefly, $250 \mathrm{ng}$ of genomic DNA was double digested with $6 \mathrm{U}$ of EcoRI (Promega) and MseI (NE Biolabs) in a $25-\mu \mathrm{l}$ reaction mixture (10 mM Tris-acetate $\mathrm{pH} 7.5,10 \mathrm{mM} \mathrm{Mg-}$ acetate, $50 \mathrm{mM}$ K-acetate, $5 \mathrm{mM}$ DTT, $1 \mathrm{X} \mathrm{BSA}$ ) for $4 \mathrm{~h}$ at $37^{\circ} \mathrm{C}$. Restrictions were terminated by heat inactivation for $20 \mathrm{~min}$ at $65^{\circ} \mathrm{C}$. The resulting fragments were ligated to adapter sequences by addition of an equal volume of ligation solution comprised of $0.25 \mu \mathrm{M}$ EcoRI adapter, $2.5 \mu \mathrm{M}$ MseI adapter, $1 \mathrm{X}$ enzyme reaction buffer, and $67 \mathrm{U}$ of T4 DNA ligase (400 units/ $\mu \mathrm{l}$, NE Biolabs). Incubations were performed for $16 \mathrm{~h}$ at $16^{\circ} \mathrm{C}$, and reactions were terminated by heat inactivation. The adapter-ligated DNA $(3 \mu \mathrm{l})$ was used for pre-selective amplification with primers based on the adapter sequences with one selective nucleotide at the 3 ' end $(E c o R I+A$ and $M s e I+C)$. Pre-selective amplification was performed in a $20 \mu$ l reaction mixture containing $1.5 \mathrm{mM} \mathrm{MgCl}_{2}, 0.5 \mathrm{mM}$ each dNTP, $250 \mathrm{nM}$ each primer, $1 \mathrm{X}$ enzyme reaction buffer, and $3 \mathrm{U}$ Taq DNA polymerase (Promega). Amplifications were conducted under the following conditions: $94^{\circ} \mathrm{C}$ for $2 \mathrm{~min}$; 26 cycles of $94^{\circ} \mathrm{C}$ for $60 \mathrm{~s}, 56^{\circ} \mathrm{C}$ for $60 \mathrm{~s}, 72^{\circ} \mathrm{C}$ for $60 \mathrm{~s}$; and a final elongation at $72^{\circ} \mathrm{C}$ for $5 \mathrm{~min}$. For the selective step, $1.5 \mu \mathrm{l}$ of a 5 -fold water diluted pre-selected PCR product was used as DNA template. The $20 \mu$ reaction mixture contained $1.5 \mathrm{mM} \mathrm{MgCl}, 0.2 \mathrm{mM}$ each dNTP, 250 $\mathrm{nM} E c o \mathrm{RI}+\mathrm{ANN}, 300 \mathrm{nM}$ oligo $M s e \mathrm{I}+\mathrm{CNN}, 1.6 \mathrm{U}$
Taq DNA polymerase (Fermentas), and $1 \mathrm{X}$ enzyme reaction buffer. Selective amplification was conducted under the following conditions: $94^{\circ} \mathrm{C}$ for $2 \mathrm{~min} ; 12$ cycles of $94^{\circ} \mathrm{C}$ for $30 \mathrm{~s}, 65^{\circ} \mathrm{C}$ for $30 \mathrm{~s}, 72^{\circ} \mathrm{C}$ for $60 \mathrm{~s}$; the final 23 cycles had similar conditions with the exception of a $56^{\circ} \mathrm{C}$ primer annealing temperature, and a final elongation at $72^{\circ} \mathrm{C}$ for $2 \mathrm{~min}$. Following PCR, the amplified products were mixed with an equal volume of denaturing buffer containing 95\% formamide, $10 \mathrm{mM}$ EDTA (pH 8.0), 0.2\% bromophenol blue, and 0.2\% xylene cyanol. Samples $(3 \mu \mathrm{L})$ were loaded into $5 \%(\mathrm{w} / \mathrm{v})$ polyacrylamide gels (acrylamide/bis-acrylamide, 19:1). Electrophoresis was performed at a constant power of $70 \mathrm{~W}$ for $4 \mathrm{~h}$, using a Sequi-Gen ${ }^{\circledR}$ GT (Bio Rad) apparatus. Gels were silver-stained according to the protocol described by Creste et al. [69].

Seventy-two different restriction enzyme and selective primer combinations were examined using DNA from both parents in duplicate reactions. Combinations that exhibited good profiles, and revealed a large number of loci and polymorphism rates $(\geq 20 \%)$ were selected for genotyping the $F_{1}$ population. The polymorphism rate between parents was calculated by assessing the number of bands present in one parent and absent in the other, in relationship to the total number of amplified bands.

\section{EST-SSRs amplification}

In analyzing the SUCEST database, Pinto et al. [70] identified 2005 clusters containing SSRs. Primer sets were subsequently developed from these data, and used in polymorphism analyses [70-73]. In addition, Maccheroni et al. [74] analyzed 352 and 122 sugarcane ESTs available in both public [75] and private [76] databases to establish sugarcane SSRs. Primer sets were developed from these sequences. In the present study, we used published [72-74], and non-published primer sets developed by CanaVialis/Monsanto.

EST-SSRs amplification was performed in a final volume of $10 \mu \mathrm{l}$ in 96-well thermocycler plates. Approximately $20 \mathrm{ng}$ of template DNA was mixed in a solution of $0.25 \mu \mathrm{M}$ of each forward and reverse primer, $0.2 \mathrm{mM}$ each dNTP, $2.0 \mathrm{mM} \mathrm{MgCl}_{2}$, $1 \mathrm{X}$ Colorless Go Taq buffer, and 1.0 U Go Taq Flexi DNA Polymerase (Promega). Amplifications were performed using two thermal cycling programs. The first program was conducted under the following conditions: $94^{\circ} \mathrm{C}$ for $3 \mathrm{~min} ; 31$ cycles of $94^{\circ} \mathrm{C}$ for $60 \mathrm{~s}$; primer annealing at varied temperatures for $60 \mathrm{~s}$; extension at $72^{\circ} \mathrm{C}$ for $60 \mathrm{~s}$; and a final elongation at $72^{\circ} \mathrm{C}$ for $2 \mathrm{~min}$. The second was conducted under the following cycle parameters: an initial denaturation step at $94^{\circ} \mathrm{C}$ for $5 \mathrm{~min}$; followed by 35 cycles of $94^{\circ} \mathrm{C}$ for $30 \mathrm{~s}$; primer annealing at varied temperatures for $30 \mathrm{~s}$; extension at 
$72^{\circ} \mathrm{C}$ for $30 \mathrm{~s}$; and a final elongation at $72^{\circ} \mathrm{C}$ for $60 \mathrm{~min}$. PCR products were analyzed by two methods, denoted $\mathrm{S}$ and F. Amplicons were resolved by 5\% (w/v) denaturing polyacrylamide gel electrophoresis, and silver stained (S) as above described; or capillary electrophoresis using a MegaBACE $1000^{\circledR}$ genotyping system (GE Healthcare Life Sciences). For capillary electrophoresis, forward primers were labeled with fluorescent dyes (F) (fluorophore NED or 6-FAM, Applied Biosystems), and fragments were verified with the Fragment Profiler version $1.2^{\circledR}$.

Polymorphisms between parental genotypes were assessed by amplifying 184 EST-SSRs using DNA from 'IAC66-6', 'TUC71-7', and a sample from the mapping population $\left(\mathrm{F}_{1}\right)$. The data included 33 EST-SSRs developed by Oliveira et al. [72], two from Marconi et al. [73], and three from Maccheroni et al. [74]. In addition, 146 EST-SSRs were available from CanaVialis/Monsanto (unpublished data). Results showed 41 polymorphic loci, which did segregate in the progeny sample; therefore, these loci were applied to genotype the mapping population. Details on these sugarcane EST-SSRs are presented in Table 4.

\section{Marker generation based on sugarcane retrotransposon sequences}

The principle NBS-profiling technique [77] was applied according to Hanai et al. [78] to generate markers based on two retrotransposons named scIvana_1 (GenBank Accession Number JN800016) and scAle_1 (GenBank Accession Number JN800006). Approximately $500 \mathrm{ng}$ of genomic DNA were digested with AluI, DraI, SspI, or RsaI (NE BioLabs). Digestions were performed in a final volume of $30 \mu \mathrm{l}$ using $7.5 \mathrm{U}$ of enzyme for $7 \mathrm{~h}$ at $37^{\circ} \mathrm{C}$, according to the manufacturer's recommendations. Reactions were terminated by heat inactivation $(20 \mathrm{~min}$ at $65^{\circ} \mathrm{C}$ ). Adapters were prepared by incubating equimolar amounts of LA (long arm) and SA (short arm) oligonucleotides at $65^{\circ} \mathrm{C}$ for $10 \mathrm{~min}$, and respectively cooled to $37^{\circ} \mathrm{C}$ and $25^{\circ} \mathrm{C}$ (10 min each). The SA oligonucleotide 3' end was blocked for Taq DNA polymerase extension by the addition of an amino group, but phosphorylated at the 5 ' end, which results in an adapter primer-annealing site only following the first PCR cycle. Subsequently, the digested material and a solution containing a $1.6 \mu \mathrm{M}$ adapter (when restricted with $A l u \mathrm{I}$ or $R s a \mathrm{I}$ ), or a $0.2 \mu \mathrm{M}$ adapter (when DraI or SspI was used), 1 X ligation buffer (NE BioLabs), and 67 U T4 DNA ligase (400 units/ $\mu$; NE BioLabs) were mixed in equal volumes $(30 \mu \mathrm{l})$, totaling $60 \mu \mathrm{l}$. Ligation was performed at $16^{\circ} \mathrm{C}$ for $16 \mathrm{~h}$, and terminated by heat inactivation at $65^{\circ} \mathrm{C}$ for $20 \mathrm{~min}$. The ligation products (diluted to $5 \mathrm{ng} / \mu \mathrm{L}$ ) as template DNA were used to amplify selected fragments anchored to the retrotransposon sequence. A final volume $20 \mu \mathrm{l}$ reaction mixture contained $4 \mu \mathrm{l}$ of ligation products, $300 \mathrm{nM}$ of each primer (a primer complementary to the adapter, and a primer complementary to the retrotransposon sequence, Table 5, Figure 2), $1.5 \mathrm{mM} \mathrm{MgCl}_{2}, 0.2 \mathrm{mM}$ each dNTP, 1 X buffer enzyme, and 2 U Taq DNA polymerase (Fermentas). PCR was conducted under the following conditions: an initial denaturation step at $94^{\circ} \mathrm{C}$ for $5 \mathrm{~min}$; followed by 8 cycles at $94^{\circ} \mathrm{C}$ for $45 \mathrm{~s}, 58^{\circ} \mathrm{C}\left(-1^{\circ} \mathrm{C}\right.$ per cycle) during $50 \mathrm{~s}$, and $72^{\circ} \mathrm{C}$ for $1 \mathrm{~h}: 15 \mathrm{~min} ; 25$ cycles at $94^{\circ} \mathrm{C}$ for $45 \mathrm{~s}, 50^{\circ} \mathrm{C}$ for $50 \mathrm{~s}$, and $72^{\circ} \mathrm{C}$ for $1 \mathrm{~min}$; and a final extension at $72^{\circ} \mathrm{C}$ for $10 \mathrm{~min}$. After PCR, the protocol for preparing AFLP gels was completed, followed by electrophoresis, and gel staining.

Sixteen restriction enzyme and retrotransposon complementary primer combinations (for each sugarcane retrotransposon) were examined using the DNA from both parents in duplicate reactions. Combinations that exhibited clear band distribution over the gels, and revealed polymorphism rates $\geq 15 \%$ were selected for genotyping the $\mathrm{F}_{1}$ population.

\section{Marker nomenclature, genotyping and segregation analyses}

The nomenclature adopted for AFLP primers followed the Keygene standard primer list [80] followed by the corresponding molecular size (in bp) of the band. A primer code was adopted for EST-SSR loci (ESTA, ESTB, ESTC and CV) followed by the molecular size of the allele (in bp). The retrotransposon-based locus nomenclature was an abbreviation that indicated the enzymes used in the digesting reaction (AI for AluI, DI for DraI, SI for $S s p$ I, and RI for RsaI) followed by the primer code (Table 5), and the molecular size of the fragment (in bp). Wu's [31] loci-segregation pattern notations follow all marker abbreviations e.g., D1-E35M47510 (Figure 1). We assumed the presence of a band, denoted by $A$, dominant over all $O$ or null alleles (or simplex configuration with eight homo(eo)logous copies in the sugarcane genome), independent of marker type. Loci were denoted as "D1" when 'IAC66-6' was heterozygous for band presence, and the other parent was homozygous for band absence $(A 0000000 \times 00000000)$. Loci were denoted as "D2" when 'TUC71-7' was heterozygous and 'IAC66-6' was homozygous. These loci were expected to segregate in a $1: 1$ fashion in the $\mathrm{F}_{1}$ population. " $\mathrm{C}$ " loci were heterozygous in both parents (A0000000 $x$ $A 0000000)$, and exhibited a 3:1 segregation ratio. Differences between observed and expected proportions were compared using Chi-square test, assuming a polyploid model based on single-dose markers (SDM) for analyzing segregation in outcrossing species [14]. For minimizing problems caused by multiple comparisons, the Bonferroni correction was performed. Chi-square tests and Bonferroni adjustments for the effects of multiple 
Table 4 Details on the sugarcane microsatellite loci derived from expressed sequence tags (ESTs)

\begin{tabular}{|c|c|c|c|c|c|c|c|c|}
\hline \multirow{2}{*}{$\begin{array}{l}\text { Marker } \\
\text { code } \\
\text { ESTA26 }\end{array}$} & \multirow{2}{*}{$\begin{array}{l}\begin{array}{l}\text { Repeat } \\
\text { motif }\end{array} \\
(\mathrm{TG})_{11}\end{array}$} & \multirow{2}{*}{$\begin{array}{l}\text { Forward primer }\left(\mathbf{5}^{\prime} \rightarrow \mathbf{3}^{\prime}\right) \\
\text { GGCAGCCCCACATCTTCCT }\end{array}$} & \multirow{2}{*}{$\begin{array}{l}\text { Reverse primer }\left(\mathbf{5}^{\prime} \rightarrow \mathbf{3}^{\prime}\right) \\
\text { GGGCACAAGCATCCGAACC }\end{array}$} & \multirow{2}{*}{$\begin{array}{l}\text { PCR }^{\mathrm{e}} \\
1\end{array}$} & \multirow{2}{*}{$\begin{array}{l}\text { AT }^{\mathbf{f}} \\
56.0\end{array}$} & \multirow{2}{*}{$\begin{array}{l}\text { D }^{\text {g }} \\
S\end{array}$} & \multicolumn{2}{|c|}{$\begin{array}{l}\text { Allele number } \\
\text { and size range }\end{array}$} \\
\hline & & & & & & & 4 & 172-186 \\
\hline ESTA48 ${ }^{\text {a }}$ & $(\mathrm{CA})_{8}$ & AGCAACTCCGGCCTCTCCTG & CTITCTGTITGCTCCTCCGTCTG & 1 & 62.7 & S & 10 & 233-295 \\
\hline ESTA53 ${ }^{a}$ & $(\mathrm{TG})_{8}$ & TGGAAATGGCAGCTGGTCTCGT & ATGCACGTACCAGAGGGAGATTTG & 1 & 58.9 & S & 9 & 168-192 \\
\hline ESTA61 a & $(\mathrm{AT})_{12}$ & ACCTCAGTCTCCTCCTCAACC & TATACTACACATGCACAGGCTACG & 1 & 56.4 & S & 5 & $236-246$ \\
\hline ESTB14 ${ }^{\text {a }}$ & $(\mathrm{CGT})_{8}$ & TGAGGGAATGAATGGACTGG & CCACCACCACCATACCTGTC & 1 & 52.0 & S & 9 & 285-315 \\
\hline ESTB55 ${ }^{\text {a }}$ & $(\mathrm{CCA})_{5}$ & CTTCTTGGCCTTGGCGTTACTGA & GCTAGCTGGCCCCATTTCCTCT & 1 & 60.0 & S & 3 & $118-124$ \\
\hline $\mathrm{ESTB} \mathrm{a}^{\mathrm{a}}$ & $(T \mathrm{TG})_{10}$ & AGCCGCAATGAATCCAACTG & CTCTAGCTCCGACGATGATACCTC & 1 & 61.0 & S & 8 & $157-206$ \\
\hline ESTB82 ${ }^{a}$ & $(\mathrm{CGT})_{9}$ & CGTCGATCGAGATGAAGAAGG & GAAGCAGTCGTGGAAGTGGAG & 1 & 62.7 & S & 5 & $245-263$ \\
\hline ESTB94 ${ }^{\text {a }}$ & $(\mathrm{CTT})_{9}$ & GAGGCAGCCAGGCAGGTCAC & GGTGGCAGTGTTCAGGCAGATG & 1 & 61.0 & S & 10 & $210-279$ \\
\hline ESTB99 $^{\text {a }}$ & $(\mathrm{TCG})_{5}$ & GAGGTCCTTCTTGTAGTTGTATGC & GTGCCGGAGGATTTGATG & 1 & 64.7 & S & 4 & $215-224$ \\
\hline ESTB100 ${ }^{a}$ & $(\mathrm{TCG})_{6}$ & CCACGGGCGAGGACGAGTA & GGGTCCTTCTTCGCCTCGTG & 1 & 64.7 & S & 13 & $240-278$ \\
\hline ESTB118 ${ }^{a}$ & $(T \mathrm{TC})_{6}$ & CTTGGCTAGGGTITCTTGAGTCGT & CATGGCTITTGGCTTGCTTCT & 1 & 61.0 & S & 5 & $106-163$ \\
\hline ESTB189 ${ }^{\mathbf{b}}$ & $(\mathrm{TCA})_{10}$ & GTAAGGAAGAAGCAACAAACAACAG & GATTCGATGCAACTCTCCTGTAAA & 1 & 60.0 & S & 5 & $261-280$ \\
\hline ESTB191 ${ }^{\mathbf{b}}$ & $(\mathrm{GCT})_{5}$ & GCGCCATCAGGGAAGCCAAAAC & GCGCGTGCGAGCAGATGAAC & 1 & 60.0 & S & 5 & $213-226$ \\
\hline ESTC80 ${ }^{a}$ & $(\mathrm{ATTC})_{3}$ & ATTCTTCTCCCCCTGTTGTGC & GTCGCCAGATCGCTITCGTT & 1 & 58.9 & S & 7 & $188-292$ \\
\hline $\mathrm{CV}_{0} 6^{\mathrm{c}}$ & $(\mathrm{AATT})_{13}$ & TCTCAAGCTTCGCCAGCTA & TGGCTCGGCTGTAGGAATTA & 2 & 60.0 & S & 3 & $188-230$ \\
\hline $\mathrm{CV}_{11}{ }^{\mathrm{c}}$ & $(\mathrm{GAA})_{6}$ & TGGCATGTGTCATAGCCAAT & CCCCAACTGGGACTITTACA & 2 & 60.0 & S & 6 & $227-242$ \\
\hline $\mathrm{CV}_{22}{ }^{\mathrm{c}}$ & $(A G G G) 5$ & CACTACTCGCCCCGATTTC & CGAGTGCTTCTCCATCTGC & 2 & 64.0 & $\mathrm{~F}$ & 8 & $140-166$ \\
\hline $\mathrm{CV}_{23}{ }^{\mathrm{c}}$ & $(\mathrm{GGAA})_{7} /(\mathrm{AGG})_{6}$ & GAACTGCTCACTGGCTCCTC & GTAGAAGTCCGTCGCCGTAA & 2 & 64.0 & $\mathrm{~F}$ & 9 & $150-206$ \\
\hline $\mathrm{CV}_{2} 4^{\mathrm{c}}$ & $(\mathrm{CCAA})_{5} /(\mathrm{CACCT})_{4}$ & TCGGAGAAGTTGACCGAGTT & GGTTAAGAGTTGGGGCCTTC & 2 & 60.0 & $\mathrm{~F}$ & 7 & $187-205$ \\
\hline $\mathrm{CV}_{2} 9^{\mathbf{d}}$ & $(\mathrm{ATCT})_{14}$ & TCGCGTCCACCAATGTAACC & GCGTGCATCGCTTGTGTCTT & 2 & 64.0 & $\mathrm{~F}$ & 10 & $85-133$ \\
\hline $\mathrm{CV}_{37}{ }^{\mathrm{d}}$ & $(\pi T C)_{15}$ & GGATGGACGACGTGTCCTGG & ATAAAGTGGCCGCTTGGATTGA & 2 & 64.0 & $\mathrm{~F}$ & 6 & 117-155 \\
\hline $\mathrm{CV}_{38}{ }^{\mathbf{d}}$ & $(\mathrm{CTTT})_{18}$ & GAAGCAGGGGCCTCAAGTTG & GTCAAACAGGCGATCTGGCTC & 2 & 64.0 & F & 9 & 109-199 \\
\hline $\mathrm{CV} 46^{\mathrm{c}}$ & $(\text { GGTAA })_{11}$ & TGTTCCAAGTTCATGCGCTCC & ATGCATGCAGGTTCAAAAGCAG & 2 & 64.0 & $\mathrm{~F}$ & 5 & $146-188$ \\
\hline $\mathrm{CV}_{5} 1^{\mathrm{c}}$ & $(\mathrm{TGT})_{13}$ & CTACCCCAACTTGCTTGGGAC & GACTGGAACAAAGACGGACTG & 2 & 64.0 & $\mathrm{~F}$ & 3 & $147-160$ \\
\hline $\mathrm{CV}_{5} 3^{\mathrm{c}}$ & $(\mathrm{AAAAT})_{5} /\left(\mathrm{TTTAT}_{6}\right.$ & CCCCACCGTAGCTTGTGCAT & AAACGTGCACATGCTTGTATGC & 2 & 64.0 & $\mathrm{~F}$ & 7 & $160-183$ \\
\hline $\mathrm{CV} 58^{c}$ & $(\text { ATAGAT) })_{10}$ & CGGGTAGTTAGGAGGAGATGG & GTCATCCATTTTGGAACGAATGG & 2 & 64.0 & F & 6 & 153-195 \\
\hline $\mathrm{CV} 78^{\mathrm{c}}$ & $(\mathrm{CTGTG})_{9}$ & ACGAGGCCACCATAGAACATG & GCAATTGGGAGGAGAGGAATG & 2 & 64.0 & $\mathrm{~F}$ & 9 & $144-203$ \\
\hline $\mathrm{CV}_{79^{c}}^{\mathrm{c}}$ & $(\text { CTATAT })_{11} /(\text { TATAGA })_{6}$ & GGCACTGCTGGTGGTTGATTG & TCCCACATCAAGAGGCAGCTA & 2 & 64.0 & $\mathrm{~F}$ & 7 & 136-197 \\
\hline $\mathrm{CV}_{8} 6^{\mathrm{c}}$ & $(\mathrm{AATT})_{8}$ & CCTCAGCAGCCCAAAGTCCT & GTCGGAATCAGCCGGATTAGC & 2 & 64.0 & $\mathrm{~F}$ & 5 & 159-187 \\
\hline $\mathrm{CV}_{91}{ }^{\mathrm{c}}$ & $(\mathrm{GCC})_{6} /(\mathrm{GCA})_{6}$ & AAAGGAAATCGCCCTCCGTCT & CCGATGATGAGCCAGCAATCC & 2 & 64.0 & $\mathrm{~F}$ & 8 & $175-197$ \\
\hline $\mathrm{CV}_{94}{ }^{\mathrm{c}}$ & $(\mathrm{AAAAAG})_{5} /(\mathrm{CGT})_{5}$ & GGCAGGCCAAGATGAATGAAG & AGCACAGCGGAGGGTACGG & 2 & 64.0 & $\mathrm{~F}$ & 4 & $187-205$ \\
\hline $\mathrm{CV} 100^{\mathrm{c}}$ & $(\mathrm{GAG})_{13}$ & CTGTTGAGGAGCCGGATGAG & CTCTTCCGATGGCTCGGTCT & 2 & 64.0 & $\mathrm{~F}$ & 9 & $222-256$ \\
\hline CV101 ${ }^{c}$ & $(\mathrm{ATC})_{23}$ & GTCGTCGTCGTCACGATCATC & AGTTGACGGCATGGTTCTTGC & 2 & 64.0 & F & 11 & $111-180$ \\
\hline CV104 ${ }^{c}$ & $(\mathrm{TCCTG})_{5}$ & GATTITCGACTGTGCGCTTGG & AAGTTCTCTGCCGGAGCAAAC & 2 & 64.0 & $\mathrm{~F}$ & 6 & $133-158$ \\
\hline $\mathrm{CV} 106^{\mathrm{c}}$ & $(\mathrm{GGC})_{8}$ & AAACAGAGCATACTCGAGGCC & TGACGAGG & 2 & 64.0 & $\mathrm{~F}$ & 6 & $146-161$ \\
\hline CV115 & $(\mathrm{TCACAG})_{10} /(\mathrm{GTA})_{6} /(\mathrm{AGA})_{5}$ & GTCCATGTCCATCCATGATCC & GGAGCTCCGTCTTCTTGTTAC & 2 & 60.0 & S & 6 & $150-174$ \\
\hline $\mathrm{CV} 119^{\mathrm{c}}$ & $(\mathrm{AAAAC})_{7}$ & TATCTCTCCTTGGTITGGATGG & CACCCTACCAAATACCACAACA & 2 & 64.0 & F & 5 & $121-175$ \\
\hline $\mathrm{CV} 128^{c}$ & $(\mathrm{GCA})_{13}$ & AGGGCAACGGAGTCTTCGAC & CTGAACTCCGATGTGCTGGTG & 2 & 60.0 & $\mathrm{~F}$ & 5 & 147-168 \\
\hline $\mathrm{CV} 135^{\mathrm{c}}$ & $(\mathrm{AAG})_{16}$ & AGCAAAACCAGCCTTCCCTTC & CTGTITGTTCTGCTTGCTTGC & 2 & 64.0 & $\mathrm{~F}$ & 6 & 129-159 \\
\hline CV144 ${ }^{c}$ & $(\mathrm{TCTCCG})_{5}$ & GCGCCTCCGTGGATAAGAATC & ССTTCCCCTACAGCGCCTAC & 2 & 64.0 & $\mathrm{~F}$ & 5 & $146-164$ \\
\hline
\end{tabular}

a, b, c, d Develop by Oliveira et al. [72], Marconi et al. [73], CanaVialis (unpublished); Maccheroni et al. [74], respectively.

e PCR program as described in Material and Methods.

${ }^{f}$ Annealing temperature in the amplification reaction.

${ }^{9}$ D: Silver-stained polyacrylamide gel electrophoresis (S) or fluorescence-based automated capillary electrophoresis (F) for the detection of EST-SSR alleles.

${ }^{\mathrm{h}}$ Observed number of alleles per locus and their size ranges in bp. 
Table 5 Primer sequences used for the generation of sugarcane retrotransposons-based markers

\begin{tabular}{|c|c|}
\hline Primer & Sequence $5^{\prime} \rightarrow 3^{\prime}$ a \\
\hline $\begin{array}{l}\text { Short arm oligonucleotide } \\
\text { (AS) }\end{array}$ & TGGGATCTATACTT - $\mathrm{H}_{2} \mathrm{~N}$ \\
\hline $\begin{array}{l}\text { Long arm oligonucleotide } \\
\text { (LA) }\end{array}$ & ACTCGATTCTCAACCCGAAAGTATAGATCCCA \\
\hline Adapter primer (AP) & ACTCGATTCTCAACCCGAAAG \\
\hline sclvana1_SSAP1 (sIvSI) & CAAGCCCTTAATAGCAGAAA \\
\hline sclvana1_GagRev (slvGR) & TCCCTGTATACAACCCTGTC \\
\hline sclvana1_LTR1 (sIVLI) & AGTCCTGCTCCCAGTTATCA \\
\hline sclvana1_LTR2 (sIVLII) & GTCGCCTGGGTGTGTTATC \\
\hline scAle1_LTRr (sAlLr) & ATACATGGGCCACATGGG \\
\hline scAle1_RT (sAIRT) & CCTCCCDTCCTCGACCTTC \\
\hline scAle1_LTR1 (sAlLI) & CCATGWGRCTAGGCCCATGTGGC \\
\hline scAle1_LTR2 (sAlLI) & GGGGTGTTGGAGTGTGATTG \\
\hline
\end{tabular}

comparisons were performed using the software $\mathrm{R}$, v. 2.13.0 [81]. Loci with segregation distortion were not included in linkage analysis.

\section{Linkage analyses, map construction, and identification of sugarcane homo(eo)logous groups}

All linkage analyses were performed using OneMap software [82]. Version 2.0-1 was preferred to construct a multipoint maximum likelihood linkage map applying a Hidden Markov Model approach [83].

Firstly, co-segregation groups (CGs) were established using a LOD score $\geq 6.0$, and a recombination fraction $\leq$ 0.35 . For groups with six or less markers, the best order was obtained by comparing all possible orders choosing the one with highest likelihood using the algorithm implemented in the command named "compare". To obtain the best order for larger groups (more than six markers), the command "order.seq" was applied. In this case, the likelihood was the criteria used to place the markers along the CGs under a multipoint approach, as validated by Mollinari et al. [84]. Additionally, the "ripple" command was used to check for alternative orders, as well a visual inspection on the matrix containing the pairwise recombination fractions and LOD scores (heatmaps) for the CGs. The commands "compare", "order.seq" and "ripple" were similar to those in the MAPMAKER/EXP software [17]. Finally, multipoint estimates of recombination fractions were calculated and converted into linkage distances using the Kosambi map function [85]. Map drawings were generated using MapChart 2.2 [86].

Due to the multiallelic nature and known polymorphisms, EST-SSR loci are valuable in recognizing homo(eo) logous groups (HGs) in sugarcane. Initially, CGs were assigned to HGs if they contained at least two of the same EST-SSRs. In addition, CGs were putatively added if they contained an EST-SSR locus in common with the HG [28,30,32,54]. Using this practice, two HGs were established, I and IV. Then due to the insufficient amount of SSRs, in a number of instances only one locus was used to assign CGs to the following putative HGs, II, III, V, VI and VII [30,32]. We applied Roman numerals to denote HGs; within each HG, CGs were classified in a descending order according to size (in $\mathrm{cM}$ ). The unassigned groups were designated $\mathrm{U}$, and also classified according to their size.

Finally, to test if scIvana_1-based markers have a tendency to be clustered along the genome, we used an approach similar to the one presented by Echt et al. [87]. The genetic map was divided in $10 \mathrm{cM}$ bins and the number of scIvana_1-based markers in each interval was recorded. If markers were randomly distributed, they would follow a Poisson distribution [47], defined as $\mathrm{P}(\mathrm{x})=$ $\lambda^{x} \mathrm{e}^{-\lambda} / \mathrm{x}$ !, where $\mathrm{P}(\mathrm{x})$ is the probability function; $\mathrm{x}$ is the number of markers observed in the intervals (ranging from 0 to 3$), \lambda$ is the distribution parameter calculated as average number of markers per interval in the map. A Chi-square goodness-of-fit test was performed, with 2 sclvana_1



scAle_1

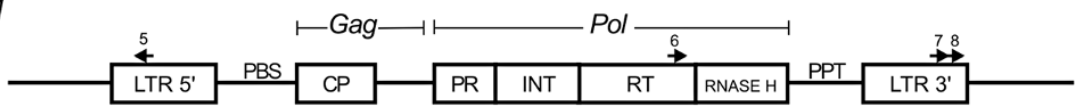

Figure 2 Structure of sugarcane retrotransposons sclvana_1 and scAle_1. Retrotransposons are LTR (long terminal repeats) consisting of elements within transcription initiation and termination sequences and detected as Gag, Pol, and Int domains that code for CP (capsid-like proteins), PR (protease), RT (reverse transcriptase), RNAase-H (ribonuclease H), and INT (integrase). Other sequences featured are PBS (primer binding sites), and PPT (polypurine tracts). Arrows indicate the primers designed for amplifying each of the elements, and synthesis direction. 1 : sclvana_1-SSAP1; 2: sclvana_1-GagRev; 3: sclvana_1-LTR1; 4: sclvana_1-LTR2; 5: scAle_1-LTRr; 6: sCAle_1-RT; 7: scAle_1-LTR1; 8: sCAle_1-LTR2. Figures were not drawn to scale and were adapted from Kumar and Bennetzen [79]. 
degrees of freedom $(\mathrm{df}=\mathrm{c}-1-\mathrm{r}$, where $\mathrm{c}$ is the number of classes and $\mathrm{r}$ is the number of estimated parameters, $\mathrm{r}=1$ ).

\section{Molecular validation of sclvana_1-based fragments}

Verification that amplified DNA fragments were derived from retrotransposon templates was conducted by excising DNA fragments from polyacrylamide gels, eluting DNA in a TE solution (10:1), and re-amplifying the DNA fragments. Five $\mu \mathrm{l}$ of the diluted DNA mixture was added to $50 \mu \mathrm{L}$ of the same solution used for retrotransposon-based marker generation, however primer concentration was $30 \mathrm{nM}$, and Taq DNA polymerase was $5 \mathrm{U}$. The PCR program was simplified and conducted under the following conditions: an initial denaturation step at $94^{\circ} \mathrm{C}$ for $5 \mathrm{~min}$; 30 cycles of $94^{\circ} \mathrm{C}$ for $30 \mathrm{~s}, 55^{\circ} \mathrm{C}$ for $30 \mathrm{~s} ; 72^{\circ} \mathrm{C}$ for $42 \mathrm{~s}$; and a final extension at $72^{\circ} \mathrm{C}$ for $10 \mathrm{~min}$. For sequencing, PCR fragments were resolved on agarose gels, purified with the QIAEX II Gel Extraction kit (QIAGEN), and cloned into pMOS Blue Blunt-Ended Cloning Kit (GE Healthcare Life Sciences). Inserts were sequenced in the forward direction. Sequencing reactions were performed according to Sanger et al. [88] using DYEnamicTM ET Dye Terminator Cycle Sequencing Kit (Amersham Pharmacia Biotech, Inc.) on an ABI 3730 system (Applied Biosystems). Sequence quality was examined using the Phred/Phrap/ Consed package [89]. Nucleotide sequences were compared to reference data available at Genbank by BLAST analysis [90].

\section{Additional files}

Additional file 1: Amplification patterns obtained from AFLP, EST-SSR, and sclvana_1-based markers for the sugarcane mapping population. Several segregating alleles are shown, as well as molecular weight standard (lane M) fragment sizes. Codes correspond to parental and $F_{1}$-progeny genotypes.

Additional file 2: Genetic information provided by the AFLP, EST-SSR and the retrotransposon sclvana_1-based loci.

\footnotetext{
Abbreviations

AFLP: Amplified Fragment Length Polymorphism; BC: Backcross; CG: Co-segregation Group; DH: Double Haploid; EST: Expressed Sequence Tag; EST-RFLP: Expressed Sequence Tag-Restriction Fragment Length Polymorphism; EST-SSR: Expressed Sequence Tag-Simple Sequence Repeat; HG: Homo(eo)logous group; IRAP: Inter-Retrotransposon Amplified Polymorphism; ISBP: Insertion Site-Based Polymorphism; LG: Linkage Group; LRR: Leucine Rich Repeat; NBS-LRR: Nucleotide Binding Site-Leucine Rich Repeat; QTL: Quantitative Trait Loci; RBIP: Retrotransposon-Based Insertion Polymorphism; REMAP: Retrotransposon Microsatellite Amplified Polymorphism; RFLP: Restriction Fragment Length Polymorphism; RIL: Recombinant Inbreed Line; SDM: Single Dose Marker; SNP: Single Nucleotide Polymorphism; SSAP: Sequence Specific Amplified Polymorphism; SSR: Simple Sequence Repeat (or Microsatellite); S-T Kinase: Serine-Threonine Kinase; SUCEST: Sugarcane Expressed Sequence Tag; TE: Transposable Element; TRAP: Target Region Amplification Polymorphism.
}

\section{Competing interests}

The authors declare that they have no competing interests.

\section{Authors' contributions}

ACP and TBRM ran AFLP, SSR and sclvana_1-based markers, created the figures and tables, and drafted the manuscript; MM and RG constructed the linkage map, and applied all statistical tests cited under and the supervision of AAFG; and MAVS and DSD described sugarcane sclvana_l and SCAle_1 retrotransposons. MLCV conceived the study, and wrote the final manuscript. APS and TM developed some of the SSRs used here. WMJr and HJJr provided the plant material as well as developed most of the SSRs. All authors read and approved the manuscript.

\section{Acknowledgements}

Authors are grateful to the following Brazilian funding institutions: Fundação de Amparo a Pesquisa do Estado de São Paulo (FAPESP, grant 2010/51708-5), Conselho Nacional de Desenvolvimento Científico e Tecnológico (CNPq), and Coordenação de Aperfeiçoamento de Ensino Superior (CAPES).

\section{Author details}

'Departamento de Genética, Escola Superior de Agricultura "Luiz de Queiroz", Universidade de São Paulo, 13418-900, Piracicaba, Brazil. ²Departamento de Botânica, Instituto de Biociências, Universidade de São Paulo, 05508-090, São Paulo, Brazil. '3Present address: Laboratório de Biotecnologia Vegetal, Instituto Agronômico do Paraná, 86047-902, Londrina, Brazil. ${ }^{4}$ CanaVialis/Monsanto Co, Condomínio Techno Park, 13069-380, Campinas, Brazil. ${ }^{5}$ Present address: Companhia Vale do Rio Doce, 20020-900, Rio de Janeiro, Brazil. ${ }^{6}$ Centro de Biologia Molecular e Engenharia Genética, Universidade Estadual de Campinas, 13083-875, Campinas, Brazil.

Received: 21 January 2012 Accepted: 13 June 2012

Published: 28 June 2012

\section{References}

1. Food and Agriculture Organization of the United Nations. http://faostat.fao.org.

2. Companhia Nacional de Abastecimento. http://www.conab.gov.br/OlalaCMS/ uploads/arquivos/11_08_30_13_41_19_boletim_cana_portugues_-_agosto_ 2011_2o_lev.pdf.

3. Bremer G: Problems in breeding and cytology of sugar cane. I - A short history of sugar cane breeding; the original forms of Saccharum. Euphytica 1961, 10:59-78.

4. Mukherjee SK: Origin and distribution of Saccharum. Bot Gaz 1957, 119:55-61.

5. Roach BT: Nobilisation of sugarcane. Proc Int Soc Sugar Cane Technol 1972, $14: 206-216$.

6. Sreenivasan TV, Ahloowalia BS, Heinz DJ: Cytogenetics. In Sugarcane improvement through breeding. Edited by Heinz DJ. Amsterdam: Elsevier; 1987:211-253.

7. Kimbeng CA, Cox MC: Early generation selection of sugarcane families and clones in Australia: A review. J Am Soc Sugar Cane Technol 2003, 23:20-39.

8. Landel MGA, Silva MA: As estratégias de seleção da cana em desenvolvimento no Brasil. Visão Agrícola 2004, 1:18-23.

9. D'Hont A, Glaszmann JC: Sugarcane genome analysis with molecular markers, a first decade of research. Proc Int Soc Sugarcane Technol 2001, 24:556-559.

10. D'Hont A, Ison D, Alix K, Roux C, Glaszmann JC: Determination of basic chromosome numbers in the genus Saccharum by physical mapping of ribosomal RNA genes. Genome 1998, 41:221-225.

11. Ha S, Moore PH, Heinz D, Kato S, Ohmido N, Fukui K: Quantitative chromosome map of the polyploid Saccharum spontaneum by multicolor fluorescence in situ hybridization and imaging methods. Plant Mol Biol 1999, 39:1165-1173.

12. D'Hont A, Grivet L, Feldmann P, Rao PS, Berding N, Glauszmann JC: Characterisation of the double genome structure of modern sugarcane cultivars (Saccharum spp.) by molecular cytogenetics. Mol Gen Genet 1996, 250:405-413.

13. Al-Janabi SM, Honeycutt RJ, McClelland M, Sobral BWS: A genetic linkage map of Saccharum spontaneum L. 'SES 208'. Genetics 1993, 134:1249-1260. 
14. Wu KK, Burnquist W, Sorrells ME, Tew TL, Moore PH, Tanksley SD: The detection and estimation of linkage in polyploids using single-dose restriction fragments. Theor Appl Genet 1992, 83:294-300.

15. Da Silva J, Honeycutt RJ, Burnquist W, Al-Janabi SM, Sorrells ME, Tanksley SD, Sobral BWS: Saccharum spontaneum L. 'SES 208' genetic linkage map combining RFLP- and PCR-based markers. Mol Breed 1995, 1:165-179.

16. Sobral BWS, Honeycutt RJ: High output genetic mapping of polyploids using PCR-generated markers. Theor App/ Genet 1993, 86:105-112.

17. Lander ES, Green P, Abrahamson J, Barlow A, Daly MJ, Lincoln SE, Newburg L: MAPMAKER: An interactive computer package for constructing primary genetic linkage maps of experimental and natural populations. Genomics 1987, 1:174-181.

18. Grivet L, D'Hont A, Roques D, Feldmann P, Lanaud C, Glaszmann JC: RFLP mapping in cultivated sugarcane (Saccharum spp.): genome organization in a highly polyploid and aneuploid interspecific hybrid. Genetics 1996, 142:987-1000.

19. Andru S, Pan Y-B, Thongthawee S, Burner DM, Kimbeng CA: Genetic analysis of the sugarcane (Saccharum spp.) cultivar 'LCP 85-384'. I. Linkage mapping using AFLP, SSR, and TRAP markers. Theor App/ Genet 2011, 123:77-93.

20. van Ooijen JW, Voorrips RE: JoinMap 3.0 Software for the calculation of genetic linkage maps. Wageningen: Plant Research International; 2001.

21. Grattapaglia D, Sederoff R: Genetic linkage maps of Eucalyptus grandis and Eucalyptus urophylla using a pseudo-testcross: Mapping strategy and RAPD markers. Genetics 1994, 137:1121-1137.

22. Mudge J, Andersen WR, Kehrer RL, Fairbanks DJ: A RAPD genetic map of Saccharum officinarum. Crop Sci 1996, 36:1362-1366.

23. Ming R, Liu S-C, Lin Y-R, da Silva J, Wilson W, Braga D, van Deynze A Wenslaff TF, Wu KK, Moore PH, Burnquist W, Sorrells ME, Irvine JE, Paterson AH: Detailed alignment of Saccharum and Sorghum chromosomes: Comparative organization of closely related diploid and polyploid genomes. Genetics 1998, 150:1663-1682.

24. Edmé SJ, Glynn NG, Comstock JC: Genetic segregation of microsatellite markers in Saccharum officinarum and S. spontaneum. Heredity 2006 97:366-375.

25. Aitken KS, Jackson PA, Mclntyre CL: Construction of a genetic linkage map for Saccharum officinarum incorporating both simplex and duplex markers to increase genome coverage. Genome 2007, 50:742-756

26. Alwala S, Kimbeng CA, Veremis JC, Gravois KA: Linkage mapping and genome analysis in a Saccharum interspecific cross using AFLP, SRAP and TRAP markers. Euphytica 2008, 164:37-51.

27. Reffay N, Jackson PA, Aitken KS, Hoarau J-Y, D'Hont A, Besse P, Mclntyre CL: Characterisation of genome regions incorporated from an important wild relative into Australian sugarcane. Mol Breeding 2005, 15:367-381.

28. Aitken $\mathrm{KS}$, Jackson PA, McIntyre CL: A combination of AFLP and SSR markers provides extensive map coverage and identification of homo (eo)logous linkage groups in a sugarcane cultivar. Theor Appl Genet 2005 110:789-801.

29. Raboin L-M, Oliveira KM, Lecunff L, Telismart $H$, Roques D, Butterfield M, Hoarau J-Y, D'Hont A: Genetic mapping in sugarcane, a high polyploid, using bi-parental progeny: identification of a gene controlling stalk colour and a new rust resistance gene. Theor App/ Genet 2006 112:1382-1391.

30. Garcia AAF, Kido EA, Meza AN, Souza HMB, Pinto LR, Pastina MM, Leite CS, da Silva JAG, Ulian EC, Figueira A, Souza AP: Development of an integrated genetic map of a sugarcane (Saccharum spp.) commercial cross, based on a maximum-likelihood approach for estimation of linkage and linkage phases. Theor App/ Genet 2006, 112:298-314.

31. Wu R, Ma C-X, Painter I, Zeng Z-B: Simultaneous maximum likelihood estimation of linkage and linkage phases in outcrossing species. Theor Popul Biol 2002, 61:349-363.

32. Oliveira KM, Pinto LR, Marconi TG, Margarido GRA, Pastina MM, Teixeira LHM, Figueira AV, Ulian EC, Garcia AAF, Souza AP: Functional integrated genetic linkage map based on EST-markers for a sugarcane (Saccharum spp.) commercial cross. Mol Breeding 2007, 20:189-208.

33. Piperidis N, Jackson PA, D'Hont A, Besse P, Hoarau J-Y, Courtois B, Aitken KS, Mclntyre $\mathrm{CL}$ : Comparative genetics in sugarcane enables structured map enhancement and validation of marker-trait associations. Mol Breeding 2008, 21:233-247.

34. The Sugarcane EST Project. http://sucest-fun.org
35. Vettore AL, da Silva FR, Kemper EL, Souza GM, da Silva AM, Ferro MIT, Henrique-Silva F, Giglioti EA, Lemos MVF, Coutinho LL, Nobrega MP, Carrer H, França SC, Bacci M Jr, Goldman MHS, Gomes SL, Nunes LR, Camargo LEA, Siqueira WJ, Van Sluys M-A, Thiemann OH, Kuramae EE, Santelli RV, Marino CL, Targon MLPN, Ferro JA, Silveira HCS, Marini DC, Lemos EGM, MonteiroVitorello CB, et al: Analysis and functional annotation of an expressed sequence tag collection for tropical crop sugarcane. Genome Res 2003, 13:2725-2735.

36. Rossi M, Araujo PG, Paulet F, Garsmeur O, Dias VM, Chen H, Van Sluys M-A, D'Hont A: Genomic distribution and characterization of EST-derived resistance gene analogs (RGAs) in sugarcane. Mol Gen Genomics 2003, 269:406-419.

37. Rossi M, Araujo PG, Van Sluys M-A: Survey of transposable elements in sugarcane expressed sequence tags (ESTs). Genet Mol Biol 2001, 24:147-154.

38. Araujo PG, Rossi M, Jesus EM, Saccaro NL Jr, Kajihara D, Massa R, Felix JM, Drummond RD, Falco MC, Chabregas SM, Ulian EC, Menossi M, Van Sluys MA: Transcriptionally active transposable elements in recent hybrid sugarcane. Plant J 2005, 44:707-717.

39. Domingues DS, Cruz GMQ, Metcalfe CJ, Nogueira FTS, Vicentini R, Alves CS, Van Sluys M-A: Analysis of plant LTR-retrotransposons at the fine-scale family level reveals individual molecular patterns. BMC Genomics 2012, 13:137.

40. Waugh R, McLean K, Flavell AJ, Pearce SR, Kumar A, Thomas BBT, Powell W: Genetic distribution of Bare-1-like retrotransposable elements in the barley genome revealed by sequence-specific amplification polymorphisms (S-SAP). Mol Gen Genet 1997, 253:687-694.

41. Kalendar R, Grob T, Regina M, Suoniemi A, Schulman A: IRAP and REMAP: Two new retrotransposon-based DNA fingerprinting techniques. Theor Appl Genet 1999, 98:704-711.

42. Baumel A, Ainouche M, Kalendar R, Schulman AH: Retrotransposons and genomic stability in populations of the young allopolyploid species Spartina anglica C.E. Hubbard (Poaceae). Mol Biol Evol 2002, 19:1218-1227.

43. Flavell AJ, Knox MR, Pearce SR, Ellis THN: Retrotransposon-based insertion polymorphisms (RBIP) for high throughput marker analysis. Plant J 1998, 16:643-650

44. Paux E, Roger D, Badaeva E, Gay G, Bernard M, Sourdille P, Feuillet C: Characterizing the composition and evolution of homoeologous genomes in hexaploid wheat through BAC-end sequencing on chromosome 3B. Plant J 2006, 48:463-474.

45. Vitte C, Ishii T, Lamy F, Brar D, Panaud O: Genomic paleontology provides evidence for two distinct origins of Asian rice (Oryza sativa L.). Mol Gen Genomics 2004, 272:504-511.

46. Paux E, Faure S, Choulet F, Roger D, Gauthier V, Martinant J-P, Sourdille $P$, Balfourier F, Le Paslier M-C, Chauveau A, Cakir M, Gandon B, Feuillet C: Insertion site-based polymorphism markers open new perspectives for genome saturation and marker-assisted selection in wheat. Plant Biotechnol J 2010, 8:196-210.

47. Basten CJ, Weir BS, Zeng ZB: QTL Cartographer: Version 1.17. Raleigh: Department of Statistics, North Carolina State University, North Carolina; 2003.

48. Garsmeur O, Charron C, Bocs S, Jouffe V, Samain S, Couloux A, Droc G, Zin C, Glaszmann J-C, Van Sluys M-A, D'Hont A: High homologous gene conservation despite extreme autopolyploid redundancy in sugarcane. New Phytol 2011, 189:629-642.

49. Besse P, Taylor G, Carroll B, Berding N, Burner D, Mclntyre CL: Assessing genetic diversity in a sugarcane germplasm collection using an automated AFLP analysis. Genetica 1998, 104:143-153.

50. Lima MLA, Garcia AAF, Oliveira KM, Matsuoka S, Arizono H, Souza CL Jr Souza AP: Analysis of genetic similarity detected by AFLP and coefficient of parentage among genotypes of sugar cane (Saccharum spp.). Theor Appl Genet 2002, 104:30-38.

51. Aitken KS, Li JC, Jackson P, Piperidis G, Mclntyre CL: AFLP analysis of genetic diversity within Saccharum officinarum and comparison with sugarcane cultivars. Aust J Agric Res 2006, 57:1167-1184.

52. Selvi A, Nair NV, Noyer JL, Singh NK, Balasundaram N, Bansal KC, Koundal KR, Mohapatra T: AFLP analysis of the phenetic organization and genetic diversity in the sugarcane complex, Saccharum and Erianthus. Gen Res Crop Evol 2006, 53:831-842.

53. Hoarau J-Y, Offmann B, D'Hont A, Risterucci A-M, Roques D, Glaszmann J$C h$, Grivet L: Genetic dissection of a modern sugarcane cultivar 
(Saccharum spp.). I. Genome mapping with AFLP markers. Theor Appl Genet 2001, 103:84-97.

54. Pastina MM, Malosetti M, Gazaffi R, Mollinari M, Margarido GRA, Oliveira KM, Pinto LR, Souza AP, van Eeuwijk FA, Garcia AAF: A mixed model QTL analysis for sugarcane multiple-harvest-location trial data. Theor Appl Genet 2012, 124:835-849.

55. Jannoo N, Grivet L, David J, D'Hont A, Glaszmann J-C: Differential chromosome pairing affinities at meiosis in polyploid sugarcane revealed by molecular markers. Heredity 2004, 93:460-467.

56. Queen RA, Gribbon BM, James C, Jack P, Flavell AJ: Retrotransposon-based molecular markers for linkage and genetic diversity analysis in wheat. Mol Gen Genomics 2004, 271:91-97.

57. Syed NH, Sorensen AP, Antonise R, van de Wiel C, van der Linden CG, van 't Westende W, Hooftman DAP, den Nijs HCM, Flavell AJ: A detailed linkage map of lettuce based on SSAP, AFLP and NBS markers. Theor Appl Genet 2006, 112:517-527.

58. Tam SM, Causse M, Garchery C, Burck H, Mhiri C, Grandbastien M-A: The distribution of copia-type retrotransposons and the evolutionary history of tomato and related wild species. J Evol Biol 2007, 20:1056-1072.

59. Bennetzen JL: Transposable element contributions to plant gene and genome evolution. Plant Mol Biol 2000, 42:251-269.

60. Dooner HK, He L: Maize genome structure variation: Interplay between retrotransposon polymorphisms and genic recombination. Plant Cell 2008, 20:249-258.

61. Kalendar R, Flavell AJ, Ellis THN, Sjakste T, Moisy C, Schulman AH: Analysis of plant diversity with retrotransposon-based molecular markers. Heredity 2011, 106:520-530.

62. Da Silva JAG, Sorrells ME, Burnquist WL, Tanksley SD: RFLP linkage map and genome analysis of Saccharum spontaneum. Genome 1993, 36:782-791.

63. Wei X, Jackson PA, McIntyre CL, Aitken KS, Croft B: Associations between DNA markers and resistance to diseases in sugarcane, and effects of population substructure. Theor Appl Genet 2006, 114:155-164.

64. Butterfield MK: Marker assisted breeding in sugarcane: a complex polyploid. PhD Thesis. Matieland, South Africa: University of Stellenbosch, Department of Agronomy, Faculty of AgriSciences; 2007.

65. McNeil MD, Hermann S, Jackson PA, Aitken KS: Conversion of AFLP markers to high-throughput markers in a complex polyploid, sugarcane. Mol Breeding 2011, 27:395-407.

66. Souza GM, Berges H, Bocs S, Casu R, D'Hont A, Ferreira JE, Henry R, Ming R, Potier B, Van Sluys M-A, Vincentz M, Paterson AH: The Sugarcane Genome Challenge: Strategies for Sequencing a Highly Complex Genome. Tropical Plant Biol 2011, 4:145-156.

67. Murray MG, Thompson WF: Rapid isolation of high molecular weight plant DNA. Nucleic Acids Res 1980, 8:4321-4325.

68. Vos P, Hogers R, Bleeker M, Reijans M, van de Lee T, Hornes M, Frijters A, Pot J, Peleman J, Kuiper M, Zabeau M: AFLP: a new technique for DNA fingerprinting. Nucleic Acids Res 1995, 23:4407-4414.

69. Creste S, Tulmann-Neto A, Figueira A: Detection of single sequence repeat polymorphisms in denaturing polyacrylamide sequencing gels by silver staining. Plant Mol Biol Rep 2001, 19:299-306.

70. Pinto LR, Oliveira KM, Ulian EC, Garcia AAF, Souza AP: Survey in the sugarcane expressed sequence tag database (SUCEST) for simple sequence repeats. Genome 2004, 47:795-804

71. Pinto LR, Oliveira KM, Marconi T, Garcia AAF, Ulian EC, Souza AP: Characterization of novel sugarcane expressed sequence tag microsatellites and their comparison with genomic SSRs. Plant Breed 2006, 125:378-384

72. Oliveira KM, Pinto LR, Marconi TG, Mollinari M, Ulian EC, Chabregas SM, Falco MC, Burnquist W, Garcia AAF, Souza AP: Characterization of new polymorphic functional markers for sugarcane. Genome 2009, 52:191-209.

73. Marconi TG, Costa EA, Miranda HRCAN, Mancini MC, Cardoso-Silva CB, Oliveira KM, Pinto LR, Mollinari M, Garcia AAF, Souza AP: Functional markers for gene mapping and genetic diversity studies in sugarcane. BMC Res Notes 2011, 4:264.

74. Maccheroni W, Jordão H, de Gaspari R, de Moura GL, Matsuoka S: Development of a dependable microsatellite-based fingerprinting system for sugarcane. Sugar Cane Int/ 2009, 27:8-13.

75. National Center for Biotechnology Information. http://www.ncbi.nlm.nih.gov/ genbankl.

76. Alellyx Applied Genomics. http://www.alellyx.com/
77. van der Linden CG, Wouters DCAE, Mihalka V, Kochieva EZ, Smulders MJM, Vosman B: Efficient targeting of plant disease resistance loci using NBS profiling. Theor App/ Genet 2004, 109:384-393.

78. Hanai LR, Santini L, Camargo LEA, Fungaro MEP, Gepts P, Tsai SM, Vieira MLC: Extension of the core map of common bean with EST-SSR, RGA, AFLP, and putative functional markers. Mol Breeding 2010, 25:25-45.

79. Kumar A, Bennetzen JL: Plant retrotransposons. Annu Rev Genet 1999, 33:479-532.

80. Standard nomenclature for AFLP $P^{\circledR}$ primers. http://www.ncbi.nIm.nih.gov/ genomes/PLANTS/AFLP_tbl.html.

81. The R Project for Statistical Computing. http://www.r-project.org.

82. Margarido GRA, Garcia AAF, Souza AP: OneMap: software for genetic mapping in outcrossing species. Hereditas 2007, 144:78-79.

83. Wu RL, Ma CX, Wu SS, Zeng ZB: Linkage mapping of sex-specific differences. Genet Res 2002, 79:85-96.

84. Mollinari M, Margarido GRA, Vencovsky R, Garcia AAF: Evaluation of algorithms used to order markers on genetic maps. Heredity 2009, 103:494-502.

85. Kosambi DD: The estimation of map distances from recombination values. Ann Eugen 1943, 12:172-175.

86. Voorrips RE: MapChart: Software for the graphical presentation of linkage maps and QTLs. J Hered 2002, 93:77-78.

87. Echt CS, Saha S, Krutovsky KV, Wimalanathan K, Erpelding JE, Liang C, Nelson CD: An annotated genetic map of loblolly pine based on microsatellite and CDNA markers. BMC Genet 2011, 12:17.

88. Sanger F, Nicklen S, Coulson AR: DNA sequencing with chain-terminating inhibitors. Proc Natl Acad Sci U S A 1977, 74:5463-5467.

89. Ewing B, Hillier L, Wendl MC, Green P: Base-calling of automated sequencer traces using Phred. I. Accuracy assessment. Genome Res 1998, 8:175-185.

90. National Center for Biotechnology Information. http://blast.ncbi.nlm.nih.gov/ Blast.cgi.

doi:10.1186/1471-2156-13-51

Cite this article as: Palhares et al:: A novel linkage map of sugarcane with evidence for clustering of retrotransposon-based markers. BMC Genetics 2012 13:51.

\section{Submit your next manuscript to BioMed Central and take full advantage of:}

- Convenient online submission

- Thorough peer review

- No space constraints or color figure charges

- Immediate publication on acceptance

- Inclusion in PubMed, CAS, Scopus and Google Scholar

- Research which is freely available for redistribution 